\title{
Selective killing of homologous recombination-deficient cancer cell lines by inhibitors of the RPA:RAD52 protein-protein interaction
}

\author{
Mona Al-Mugotir, Jeffrey J. Lovelace, Joseph George, Mika Bessho, Dhananjaya Pal, \\ Lucas Struble, Carol Kolar, Sandeep Rana, Amarnath Natarajan, Tadayoshi Bessho*, \\ Gloria E. O. Borgstahl $\mathbb{B}^{*}$
}

\author{
The Eppley Institute for Research in Cancer and Allied Diseases, Fred \& Pamela Buffett Cancer Center, \\ University of Nebraska Medical Center, Omaha, Nebraska, United States of America \\ * gborgstahl@unmc.edu (GEOB); tbessho@unmc.edu (TB)
}

\section{Abstract}

Synthetic lethality is a successful strategy employed to develop selective chemotherapeutics against cancer cells. Inactivation of RAD52 is synthetically lethal to homologous recombination (HR) deficient cancer cell lines. Replication protein A (RPA) recruits RAD52 to repair sites, and the formation of this protein-protein complex is critical for RAD52 activity. To discover small molecules that inhibit the RPA:RAD52 protein-protein interaction (PPI), we screened chemical libraries with our newly developed Fluorescence-based protein-protein Interaction Assay (FluorlA). Eleven compounds were identified, including FDAapproved drugs (quinacrine, mitoxantrone, and doxorubicin). The FluorlA was used to rank the compounds by their ability to inhibit the RPA:RAD52 PPI and showed mitoxantrone and doxorubicin to be the most effective. Initial studies using the three FDA-approved drugs showed selective killing of BRCA1-mutated breast cancer cells (HCC1937), BRCA2mutated ovarian cancer cells (PE01), and BRCA1-mutated ovarian cancer cells (UWB1.289). It was noteworthy that selective killing was seen in cells known to be resistant to PARP inhibitors (HCC1937 and UWB1 SYr13). A cell-based double-strand break (DSB) repair assay indicated that mitoxantrone significantly suppressed RAD52-dependent singlestrand annealing (SSA) and mitoxantrone treatment disrupted the RPA:RAD52 PPI in cells. Furthermore, mitoxantrone reduced radiation-induced foci-formation of RAD52 with no significant activity against RAD51 foci formation. The results indicate that the RPA:RAD52 PPI could be a therapeutic target for HR-deficient cancers. These data also suggest that RAD52 is one of the targets of mitoxantrone and related compounds.

\section{Introduction}

Cancer cells often show dependence on unique DNA repair pathways due to frequent mutations and higher demand for DNA damage repair to sustain their active division. In cancer 
Funding: The research was supported by the Fred \& Pamela Buffett Cancer Center Support Grant (P30CA036727) pilot project funding (GB \& TB), the Nebraska Research Initiative (GB), the Nebraska Department of Health and Human Services (2015, 2017-08, 2018-11; GB); and the U. S. Department of Education GAANN (P200A120231) (GB) and Nebraska NASA EPSCoR Space Grant (MAM) for student fellowships.

Competing interests: The authors have declared that no competing interests exist. therapy design, it is desirable to target factors that are dispensable for normal cells, thus sparing them from collateral damage [1]. Coupling maladaptive mutations in cancer with pharmacological inactivation of another target to induce selective cell death is called synthetic lethality [2]. This approach promises minimization of side effects that exhaust patients and has the potential to lift the roadblocks for the treatment of aggressive subtypes of cancers for which there are currently no effective therapies. Ovarian high-grade serous carcinoma (HGSC) and triple-negative breast cancer (TNBC), for example, are among the most lethal subtypes characterized by a poor prognosis, high rate of reoccurrence and metastasis $[3,4]$. Many patients with these specific cancer subtypes harbor somatic mutations in $B R C A 1$ or $B R C A 2$, or other homologous recombination (HR) genes, which inspired the development of targeted therapeutics [3-7]. Poly(ADP-ribose) polymerases (PARP) catalyze the polymerization of ADP-ribose moieties and facilitate base excision repair (BER) and single-strand break (SSB) repair. PARP inhibitors (PARPi) impair SSB repair and cause the formation of DSBs [8]. PARPi also inhibits the dissociation of PARP from DNA damage sites, and the trapped PARP induces replicationdependent DSBs. Cancer cells with defects in HR repair show synthetic lethality with PARP and are selectively vulnerable to DSBs generated by PARPi [9]. Despite the promising successes of PARPi in pre-clinical settings, in clinical trials, patients commonly acquire resistance to PARPi [10].

Since the discovery of synthetic lethality of PARPi with BRCA1/2-deficient cancer cell lines, there have been many studies to discover other synthetic lethality interactions related to DNA repair $[11,12]$. The deletion of RAD52 was discovered to be synthetically lethal with deficiencies in HR repair $[13,14]$. RAD52 participates in HR repair and is conserved throughout eukaryotes. In mammalian cells, RAD52 deletion does not compromise HR repair; however, the synthetic lethality of RAD52 inactivation with a BRCA-mediated HR deficiency indicates a critical role for RAD52-mediated DNA repair pathway(s) in the absence of BRCA-mediated HR repair [15]. Recent studies showed that RAD52 is involved in multiple DNA repair pathways, including a BRCA-independent HR repair involving RAD51 [16], single-strand annealing (SSA) [17], break-induced replication (BIR) repair [18, 19], RNA-templated double-strand break (DSB) repair [20, 21], and transcription-associated HR involving XPG [22]. However, how RAD52 activity helps HR-deficient cancers to survive is not clear.

Several studies have explored targeting RAD52 to attack cancer cells with some success. MicroRNA-302 was found to reduce the expression of AKT1 and RAD52, making breast cancer cells more sensitive to radiation [23]. A peptide F79 aptamer targeting the RAD52 DNA binding domain induced synthetic lethality in HR-deficient leukemia without affecting normal cells and enhanced the effect of already-approved drugs [24]. The small molecule 6-hydroxyDL-dopa (6-OH-dopa) was identified as an allosteric inhibitor of the RAD52 ssDNA binding domain with an $\mathrm{IC}_{50}$ of $1.1 \mu \mathrm{M}$, but unfortunately, it is also neurotoxic and induces Parkinson's disease [25]. Interestingly, both F79 peptide and 6-OH-dopa break up RAD52 rings in agreement with our earlier results [26]. Other RAD52 small molecule inhibitors (SMIs) were identified from screens based on annealing activity and by docking to the ssDNA binding site. Of these, the compounds D-G23, D-I03, AICAR, A5'MP, epigallocatechin, and epigallocatechin-3-monogallate appear to be the most effective [27-29].

In this study, we took a different approach and targeted the RPA:RAD52 protein-protein interaction (PPI). RAD52 contains several interaction domains [30, 31]. The self-association domain in the N-terminal half of RAD52 is responsible for the formation of a thermally-stable ring of monomers with residues 160 to 209 reaching over and hugging the adjacent monomer [31-33]. Each RAD52 monomer binds four nucleotides, and two ssDNA binding sites were found-one in a positively-charged groove and the other on the outside of the ring [34,35]. Biophysical data showed that RAD52 is a monomer when bound to RPA [26]. There are two 
domains on RAD52 involved in RPA binding that correspond to two domains on RPA that bind RAD52 [36]. These PPIs and ssDNA binding sites could be essential for RAD52 DNA repair activities. In the process of repairing a DSB, ssDNA tails are enzymatically created and bound by RPA. Then RAD52 comes along and binds RPA before binding ssDNA. There is a hand-off of ssDNA from RPA to RAD52. In fact, the RPA:RAD52 complex is required for RAD52 foci formation [37] at DSBs and is required for SSA of longer plasmid DNA [38].

In this report, we conducted a high throughput screen (HTS) for SMIs targeting RPA: RAD52 PPI using our newly developed Fluorescence-based protein-protein Interaction Assay (FluorIA) [39]. Over 101,500 compounds were screened from three different chemical libraries. Eleven candidate hits were obtained, five of which showed strong inhibition of RPA: RAD52 PPI as determined by their low half-maximal, effective concentration $\left(\mathrm{EC}_{50}\right)$ values in vitro. Three hits were the following FDA-approved drugs: quinacrine, mitoxantrone, and doxorubicin. Cancer cell lines lacking BRCA1 or BRCA2 functions demonstrated selective sensitivity to quinacrine, mitoxantrone, and doxorubicin. Furthermore, mitoxantrone inhibited SSA, radiation-induced RAD52 foci formation and the RPA:RAD52 PPI in cells. These early results indicate that inhibition of RPA:RAD52 PPI appears to inhibit RAD52-mediated DNA repair and that mitoxantrone may be a potent RAD52 inhibitor.

\section{Results}

\section{High throughput screening to identify SMIs of RPA:RAD52 PPI with FluorIA}

To identify SMIs of the RPA:RAD52 PPI, three chemical libraries were screened using FluorIA (Table 1). No hits were obtained from SelleckChem Kinase Inhibitor Library, but three hits came from the Prestwick library, and eight hits were obtained from the Chembridge library. In total, eleven hits were found (Fig 1A), and their ability to inhibit the RPA:RAD52 PPI was ranked using FluorIA (Fig 1B). Interestingly, FDA-approved drugs, mitoxantrone, and doxorubicin were the most potent inhibitors in FlourIA $\left(\mathrm{EC}_{50}\right.$ values of 29.7 and $10.1 \mu \mathrm{M}$, respectively; Table 2). The Chembridge hit 5316833 came in third place with an $\mathrm{EC}_{50}$ of $66 \mu \mathrm{M}$.

\section{Selective cytotoxicity of quinacrine, mitoxantrone, and doxorubicin in HR- deficient cancer cell lines}

We were curious to see if RPA:RAD52 PPI inhibitors would show synthetic lethality in HRdeficient cancer cell lines, so we examined the cytotoxicity of quinacrine, mitoxantrone, and doxorubicin in cells with impaired BRCA1 or BRCA2 function. Following the 72-hour treatment with indicated concentrations of each compound, quinacrine mitoxantrone, or doxorubicin, the viability of each cell line was analyzed. The $\mathrm{EC}_{50}$ values of each compound in each cell line tested are indicated in the graphs. Mitoxantrone and doxorubicin preferentially killed the HR-deficient cancer cell lines, HCC1937, UWB1.289, and PE01 compared to their HRproficient counterparts, HCC1937+BRCA1, UWB1.289+BRCA1, and PE01C4-2, respectively (Figs 2-4). Quinacrine was similar to mitoxantrone in selectively killing HCC1937 cells (Fig 2)

Table 1. Chemical libraries screened by FluorIA and hits obtained.

\begin{tabular}{c|c}
\hline Chemical Library & Hits \\
\hline SellekChem $(355)$ & none \\
\hline Prestwick $(1200)$ & Three \\
\hline Chembridge $(100,000)$ & Eight \\
\hline
\end{tabular}

https://doi.org/10.1371/journal.pone.0248941.t001 


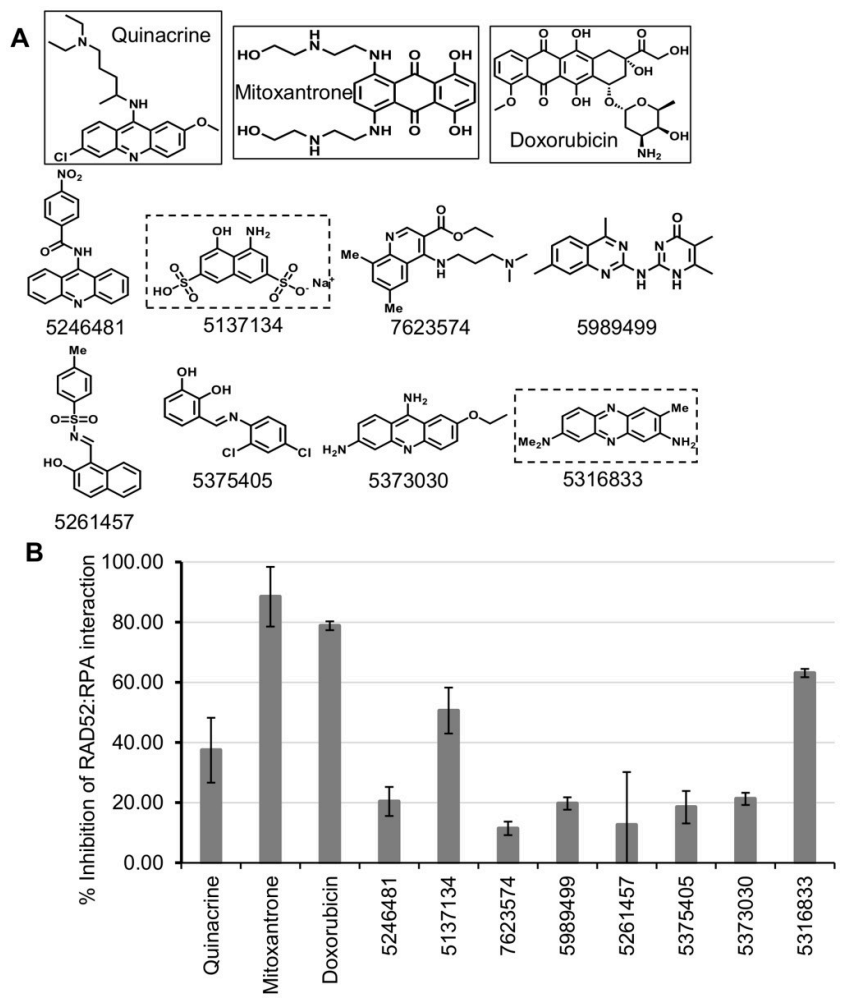

Fig 1. Identification and characterization of RPA:RAD52 inhibitors. (A) Chemical structures of the top eleven FluorIA hits. The strongest inhibitors are boxed (FDA-approved in solid-line, Chembridge dashed-line). (B) Comparison of hits for the inhibition of the RPA:RAD52 interaction at a single concentration $(62.5 \mu \mathrm{M})$. The FluorIA inhibition data for the full concentration range for each hit was included in S1 Fig.

https://doi.org/10.1371/journal.pone.0248941.g001

but killed the HR-deficient ovarian cell lines with less selectivity (Figs 3 and 4). The detection of cleaved PARP by western blotting confirmed that mitoxantrone preferentially induced apoptosis in the BRCA1-mutated UWB1.289 compared to the BRCA1-restored UWB1.289

(Fig 5).

The inhibition of PARP is also synthetically lethal to HR-deficient cancer cell lines. PARPi are effective against various BRCA-mutated cancer cell lines. However, limited success has been reported in clinical trials of PARPi with BRCA-deficient tumors. HCC1937 is reported to be insensitive to PARPi despite its BRCA1-mutated status [40-43]. Interestingly, all three compounds showed selective cytotoxicity to HCC1937 (Fig 2), indicating the RPA:RAD52 PPI is an effective target for selective killing of BRCA-mutated cancer cell line regardless of the status of synthetic lethality with PARPi. To generalize this concept, we examined the cytotoxicity of these compounds to two PARPi resistant cell lines, UWB1-SYr12 and SYr13 (Fig 3). UWB1-

Table 2. $\mathrm{EC}_{50}$ values for the strongest five inhibitors in FluorIA.

\begin{tabular}{l|c|c|c|c|c}
\hline Compound & Quinacrine & Mitoxantrone & Doxorubicin & $\mathbf{5 1 3 7 1 3 4}$ & $\mathbf{5 3 1 6 8 3 3}$ \\
\hline $\mathbf{E C}_{\mathbf{5 0}}(\boldsymbol{\mu M})$ & 97.7 & 29.7 & 10.1 & 104.7 & 66.2 \\
\hline
\end{tabular}

$\mathrm{EC}_{50}$ values obtained from a polynomial curve fitting for each compound where the response (inhibition) is tested at 15 different dose concentrations (0.03-500 $\left.\mu \mathrm{M}\right)$ in triplicate. RAD52(1-303) was used as positive control. The FluorIA inhibition data for the full concentration range for each hit was included in S1 Fig. 

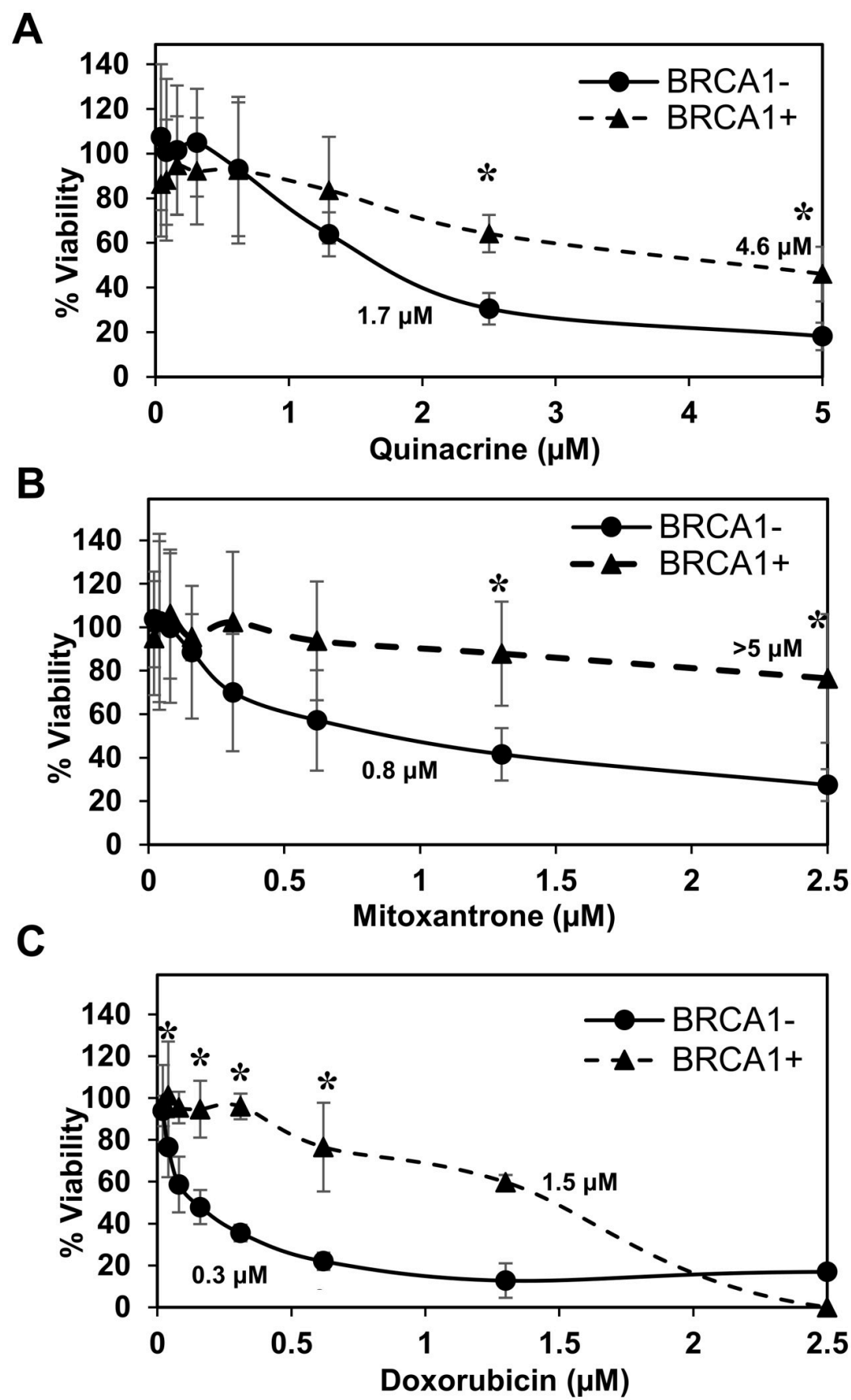

Fig 2. BRCA1-deficient HCC1937 breast cancer cell line survival assay. BRCA1-deficient HCC1937 cells corrected with wild-type BRCA1 gene (BRCA1+; closed triangle), and with an empty vector (BRCA1-; closed circle) were examined. For each experiment (Figs 2-4), cell lines were treated with nine concentrations of (A) quinacrine, (B) mitoxantrone, and (C) doxorubicin in 96 -well culture plates at $5 \times 10^{3}$ cell/well density. Each treatment point was made in sextuplicate. Treated cells were incubated for 72 hours at $37^{\circ} \mathrm{C}$ before assessing cell viability using PrestoBlue. Data were normalized to vehicle control. The experiment was repeated three times. Error bars indicate the standard deviation. Significantly different data are indicated with an asterisk. $\mathrm{EC}_{50}$ values, estimated from the graphs, are given.

https://doi.org/10.1371/journal.pone.0248941.g002

SYr12 and SYr13 are laboratory-generated PARPi-resistant cell lines derived from BRCA1mutated UWB1.289. These two cell lines gained the BRCA1-independent, ATR-dependent loading of RAD51 in HR and fork protection and restored PARPi resistance [43]. Mitoxantrone and doxorubicin showed preferential cytotoxicity to the PARPi-resistant UWB1-SYr12 

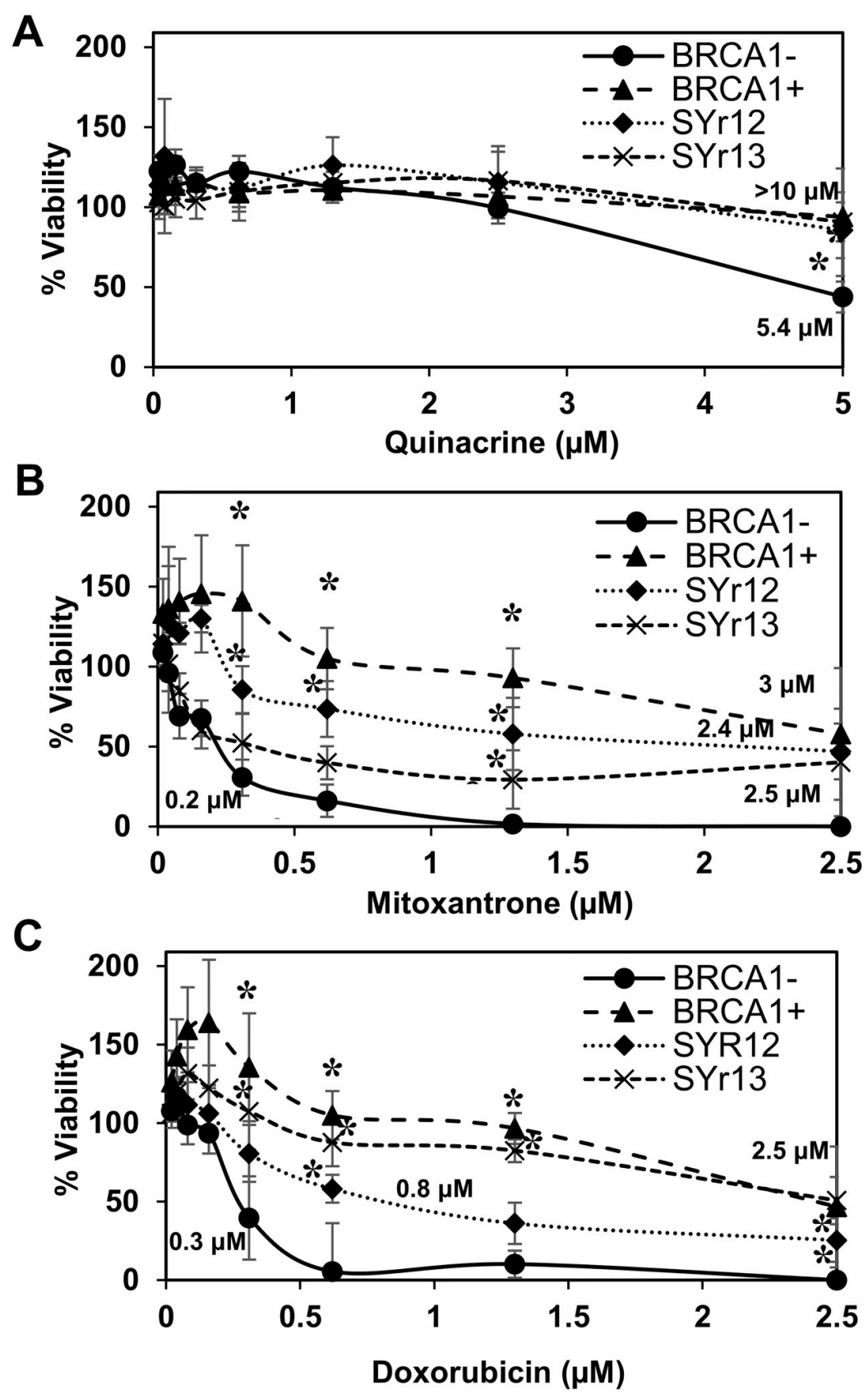

Fig 3. BRCA1-deficient UWB1.289 ovarian cancer cell line survival assay. BRCA1-deficient UWB1.289 cells corrected with wild-type BRCA1 gene (BRCA1+; closed triangle) and parental BRCA1-deficient UWB1.289 (BRCA1-; closed circle). Two PARPi-resistant cell lines derived from UWB1.289, UWB1.289.SYr12 (closed diamond) and UWB1.SYr13 (X), were also examined. Cell lines were treated with (A) quinacrine, (B) mitoxantrone, and (C) doxorubicin as described in Fig 2.

https://doi.org/10.1371/journal.pone.0248941.g003

and SYr13, although their selectivity was moderate compared to the one with parental UWB1.289 (Fig 3).

The level of RAD52 protein and DNA damage before and after mitoxantrone treatment was characterized and was found to vary between cell lines (Fig 6). For HCC1937 and UWB1 cell lines, low to negligible levels of DNA damage occurred from mitoxantrone treatment and 

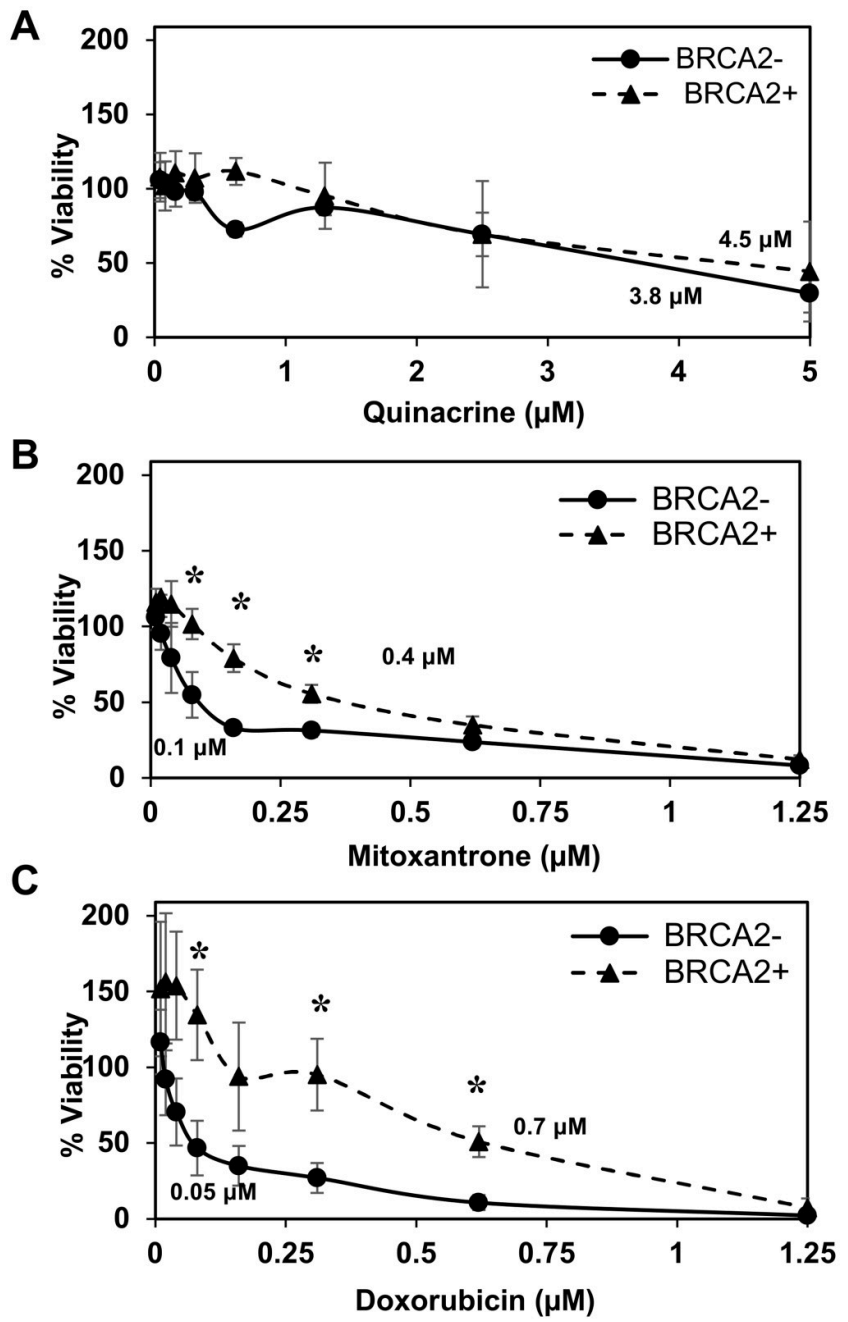

Fig 4. BRCA2-deficient PE01 ovarian cancer cell line survival assay. BRCA2-deficient PE01(BRCA2-; closed circle) and BRCA2-revertant PE01 C4-2 (BRCA2+; closed triangle) were examined. Cell lines were treated with (A) quinacrine, (B) mitoxantrone, and (C) doxorubicin as described in Fig 2.

https://doi.org/10.1371/journal.pone.0248941.g004

RAD52 levels remained relatively high. In HCC1937 cells the level of RAD52 increased with mitoxantrone treatment and in UWB1 cells the level of RAD52 decreased. Interestingly, the PE01 ovarian cancer cell line was more sensitive to mitoxantrone treatment showing a dramatic reduction in RAD52 protein and a substantial increase in DNA damage, relative to the other cell lines.

\section{Inhibition of DNA repair activities of RAD52 by mitoxantrone}

In mammalian cells, RAD52 promotes SSA but has little impact on HR. Because SSA is RAD52-mediated, but independent of BRCA1, BRCA2, and RAD51, SSA has been implicated as one of the backup DSB repair pathways in the absence of the BRCA-mediated HR repair. To examine the impact of the inhibitors of the RPA:RAD52 PPI on SSA, we employed a cellbased SSA assay. Pre-treatment of U2OS-SA and U2OS-DR cells with mitoxantrone revealed that mitoxantrone suppressed both SSA and HR (Fig 7A). Mitoxantrone preferentially suppressed the SSA activity over the HR activity at $4 \mathrm{nM}$. SSA was inhibited by $72 \% \pm 7 \%$, and $\mathrm{HR}$ 

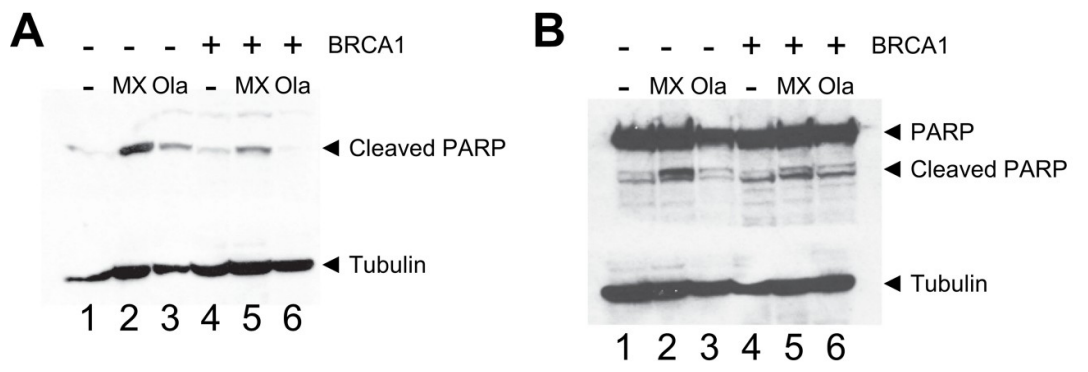

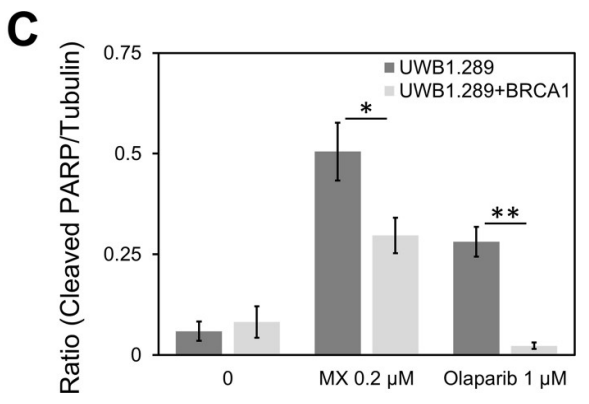

Fig 5. Mitoxantrone induces apoptosis preferentially in the BRCA1-deficient UWB1.289. UWB1.289 cells with or without restoration of the BRCA1 expression were treated with $0.2 \mu \mathrm{M}$ of mitoxantrone (MX) for three days. Olaparib (Ola) at $1 \mu \mathrm{M}$ was used as control for the induction of apoptosis. Near $\mathrm{EC}_{50}$ concentrations were selected for each compound. After the treatment with each compound, cell lysates were prepared and cleaved PARP was detected with (A) anti-cleaved PARP antibody (Cell Signaling Technology \#9541) and (B) anti-PARP antibody (Cell Signaling Technology \#9542). Tubulin detected with anti-beta-tubulin antibody (Cell Signaling Technology \#15115) was used as an internal control. (C) Ratios of cleaved PARP to tubulin were determined with ImageJ and graphed. Three independent experiments were performed and the mean values are shown. The bars indicate standard deviations. Statistical significance of differences was determined with Student t-test $\left({ }^{*} \mathrm{p}<0.05\right.$ and $\left.{ }^{* *} \mathrm{p}<0.01\right)$.

https://doi.org/10.1371/journal.pone.0248941.g005

was suppressed by $40 \% \pm 7 \%$ at $4 \mathrm{nM}$ (Fig 7B). With higher concentrations of mitoxantrone $(>6 \mathrm{nM}$ ), both SSA and HR were inhibited at similar levels, partly due to the suppression of the exogenous expression of I-SceI (Fig 7C). The cell-based DSB repair assays used in this study induce DSBs by the exogenous expression of the I-SceI endonuclease by transfection. Because mitoxantrone can inhibit transcription, we measured the expression of I-SceI and GFP by western blot analysis. DSB repair activity measured by Western blot analysis also confirmed the preferential inhibition of SSA over HR by mitoxantrone (Fig 7D and 7E).

RAD51 forms foci after X-ray radiation. The radiation-induced RAD51 foci are considered to be a surrogate marker for HR activity. RAD52 also forms foci after irradiation and the foci formation is thought to represent RAD52-mediated DNA repair processes. GFP-RAD52 and GFP-RAD51 were expressed individually in HR-restored PE01 C4-2, and the impact of mitoxantrone on radiation-induced foci formation of GFP-RAD52 and GFP-RAD51 were examined. As expected, GFP-RAD52 and GFP-RAD51 formed foci after radiation in the HRproficient PE01 C4-2 (Fig 8, left panel). Pre-treatment of PE01 C4-2 with mitoxantrone (3 $\mathrm{nM}$ ) inhibited the radiation-induced RAD52 foci formation (Fig 8, right top) while it did not suppress the radiation-induced RAD51 foci formation (Fig 8, right bottom). Thus, mitoxantrone appears to inhibit RAD52-mediated DNA repair pathways, including SSA but has little impact on the RAD51-mediated HR. These data suggest that the inhibitors of the RPA:RAD52 PPI can selectively suppress RAD52-based DNA repair without altering the RAD51-based DNA repair significantly.

\section{Discussion}

In this report, we aimed to compromise RAD52 activity by inhibiting its PPI with RPA. Our newly developed FluorIA is a PPI assay that was optimized to use in high throughput settings to screen SMIs. We successfully identified three FDA-approved drugs as the inhibitor of the RPA:RAD52 PPI. Mitoxantrone and doxorubicin, are anti-cancer drugs in clinical use and displayed RPA:RAD52 PPI inhibition in FluorIA and had the highest cytotoxicity in BRCA-deficient cancer cell lines. BRCA1 and BRCA2 cancer cell lines also demonstrated more limited sensitivity to quinacrine. Furthermore, our results showed that mitoxantrone suppressed SSA preferentially over HR repair. Mitoxantrone also inhibited X-ray induced RAD52 foci formation without affecting RAD51 foci formation. It is worth noting that experiments employing size exclusion chromatography followed by the co-immunoprecipitation of RAD52 with RPA 
A

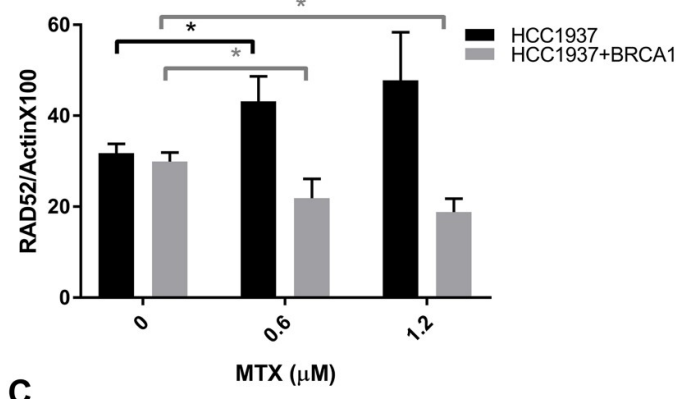

C
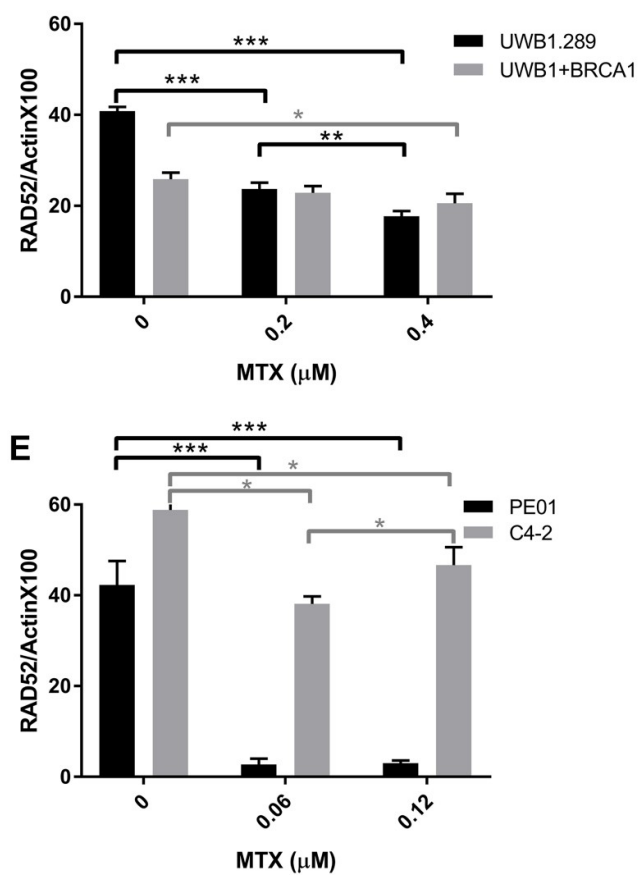

B

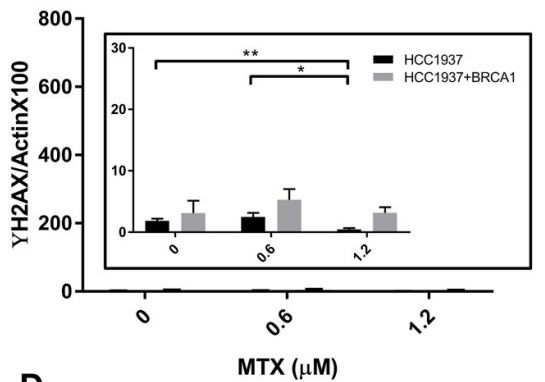

D
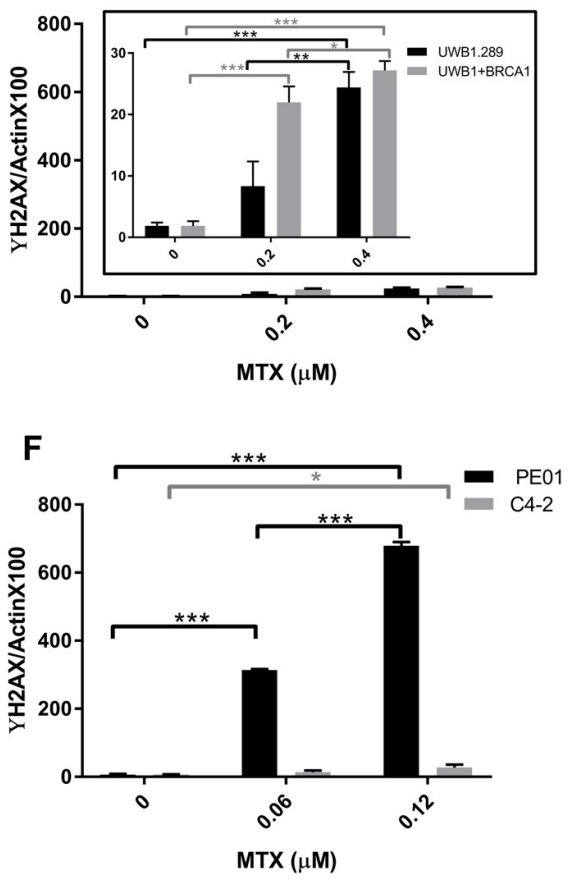

Fig 6. The effect of mitoxantrone treatment on RAD52 levels and DNA damage. (A, C, and E) RAD52 and $\gamma \mathrm{H} 2 \mathrm{AX}$ $(\mathbf{B}, \mathbf{D}$, and $\mathbf{F})$ levels were probed in the three parental (black) and (BRCA1 or BRCA2 proficient, grey) cell lines indicated was assessed with Simple Western using lysate post $72 \mathrm{~h}$ treatment with mitoxantrone at doses near their $\mathrm{EC}_{50}$ values (see Figs 2-4). Data and ANOVA statistical analyses are described in the material and methods section. Significance statistics are shown with single, double, or triple asterisks representing $\mathrm{P}<0.05, \mathrm{P}<0.005$, or $\mathrm{P}<0.0005$, respectively.

https://doi.org/10.1371/journal.pone.0248941.g006

indicate that mitoxantrone disrupts the RPA:RAD52 PPI in cells (Fig 9). Interestingly, preliminary experiments show that incubation with $3 \mathrm{nM}$ mitoxantrone disrupted the interaction of RPA with high molecular weight rings of RAD52, and only the interaction with a form of RAD52 near $66 \mathrm{kDa}$ was retained. Overall these results confirm that the RPA:RAD52 PPI is crucial for RAD52-mediated DNA repair pathways, as was previously reported [37]. In the absence of the BRCA-mediated HR repair, cells can become addicted to RAD52-based DNA repair pathways to survive. The inhibition of the interaction abrogates RAD52-mediated DNA repair pathways selectively and leads to cell death. Since RAD52 is involved in various DNA repair pathways, it is unclear which RAD52-mediated DNA repair pathway keeps the cells alive in the absence of BRCA-mediated HR. Although identification of DNA repair factors involved in each RAD52-mediated DNA repair pathway is required to reveal the mechanistic basis of the synthetic lethality of HR-deficient cancers with RAD52 inhibition, our results 
A

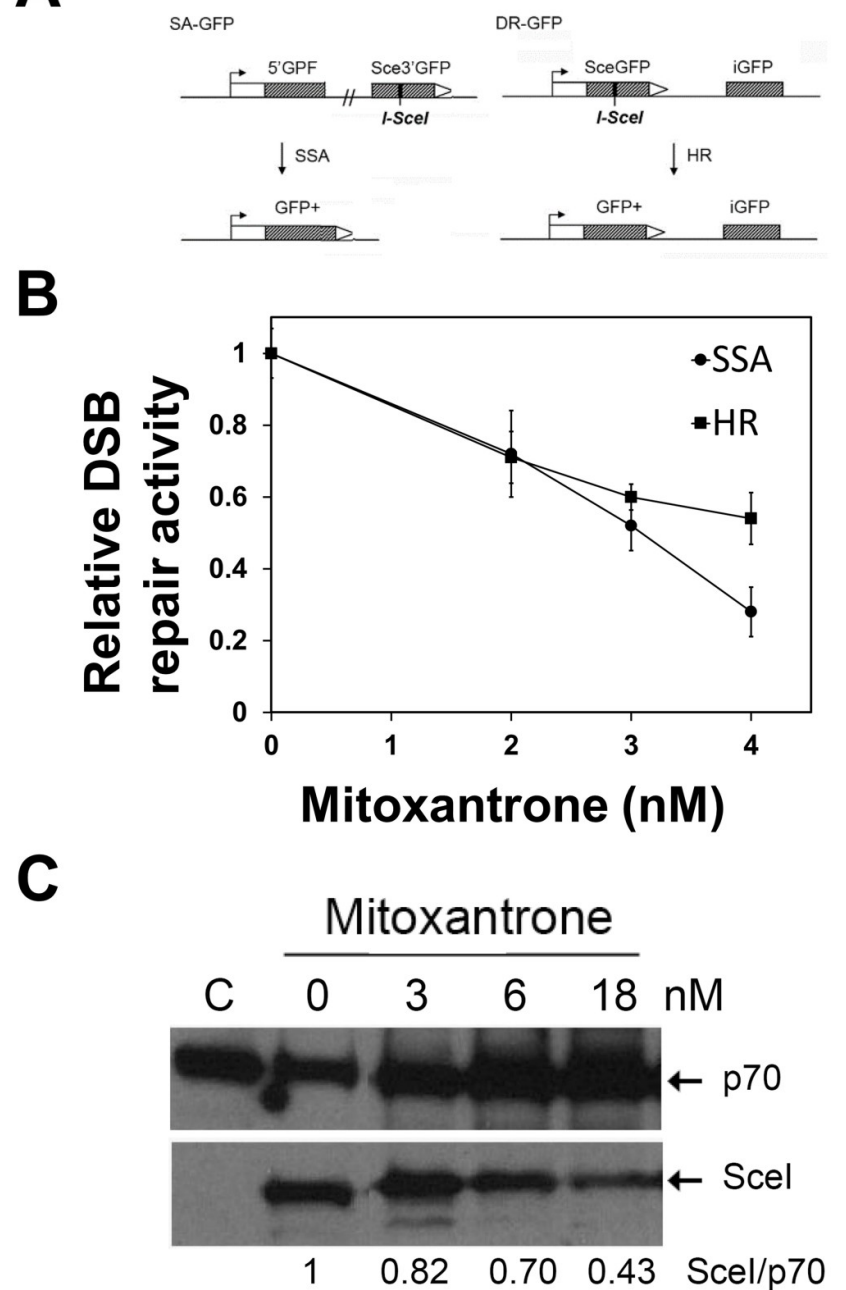

DR-GFP
D

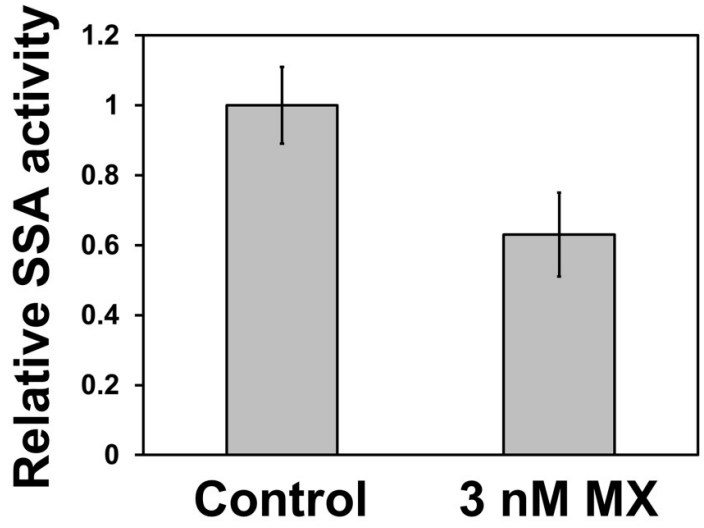

E

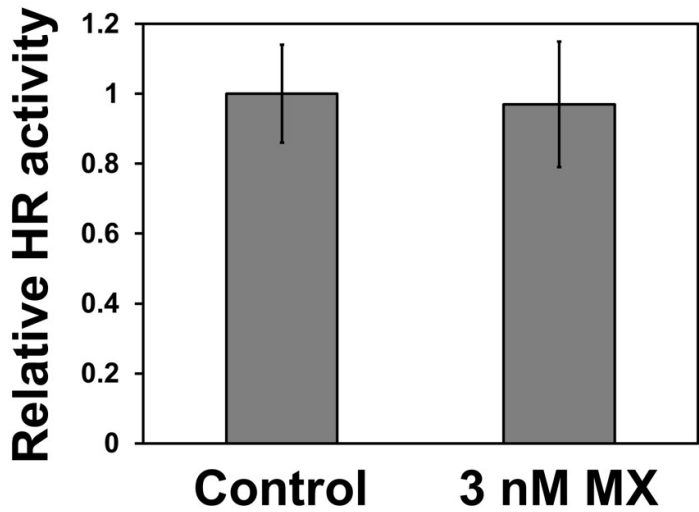

Fig 7. RAD52 inhibitor mitoxantrone selectively suppresses SSA. (A) The effect of mitoxantrone (MX) on SSA and HR were studied with cell-based DSB repair assays. U2OS-SA and U2OS-DR cells were pre-treated with mitoxantrone for two hours before transfection of the SceI-expression plasmid. Then cells were grown in the presence of mitoxantrone for three days. DSB repair activities were determined by (B) FACS analysis. FACS data are provided in S3 Fig. (C) Inhibition of the expression of I-SceI (SceI) by mitoxantrone. U2OS-SA cells were pre-treated with indicated concentrations of mitoxantrone for two hours, before I-SceI-expression vector transfection. After 72 hours incubation, the cells were harvested, and lysates were prepared. Lysate from each treatment was analyzed by $12 \%$ SDS-PAGE and the expression levels of I-SceI was determined by the western blot using anti-HA antibody. The p70 of RPA was used as a loading control. Ratios of I-SceI to p70 was obtained with ImageJ and are shown at the bottom of the image. C: control experiment without the addition of mitoxantrone. (D, E) Analysis of DSB repair activiies by western blots. Graphs showed relative DSB repair activities with mitoxantrone to control experiments without mitoxantrone. At least three independent experiments were performed. Error bars represent standard deviations. The differences between the SSA inhibition and the HR suppression by mitoxantrone were statistically significant $(\mathrm{p}<0.05$ at $4 \mathrm{nM}$, and $\mathrm{p}<0.05$ at $3 \mathrm{nM})$. Western blot data are provided in S4 Fig.

https://doi.org/10.1371/journal.pone.0248941.g007

demonstrated that the RPA:RAD52 PPI is highly likely to be essential for RAD52 addiction in BRCA-deficient cancers.

So far, mitoxantrone and doxorubicin are the best at inhibiting the RPA:RAD52 PPI, inhibiting RPA:RAD52 activity, and at selective killing. Mitoxantrone is among a class of chemotherapeutic drugs with flat polycyclic aromatic systems that can intercalate DNA [44, 45], and mitoxantrone is known to inhibit topoisomerase II $\alpha$ and to create DSBs [46]. Mitoxantrone specifically targets topoisomerase II $\alpha$ isoform, and this gives a safety advantage in patients because topoisomerase II $\alpha$ is preferentially expressed in proliferating cells while topoisomerase 
A
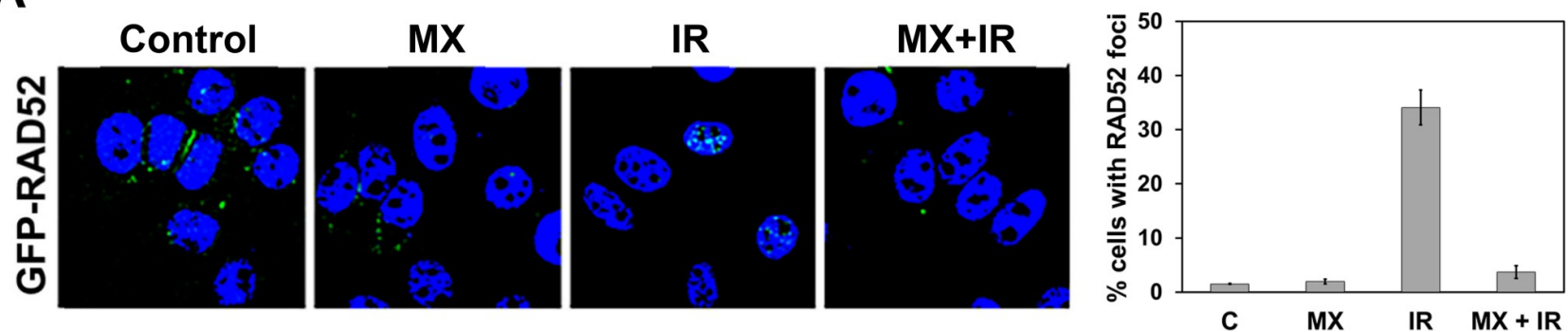

B
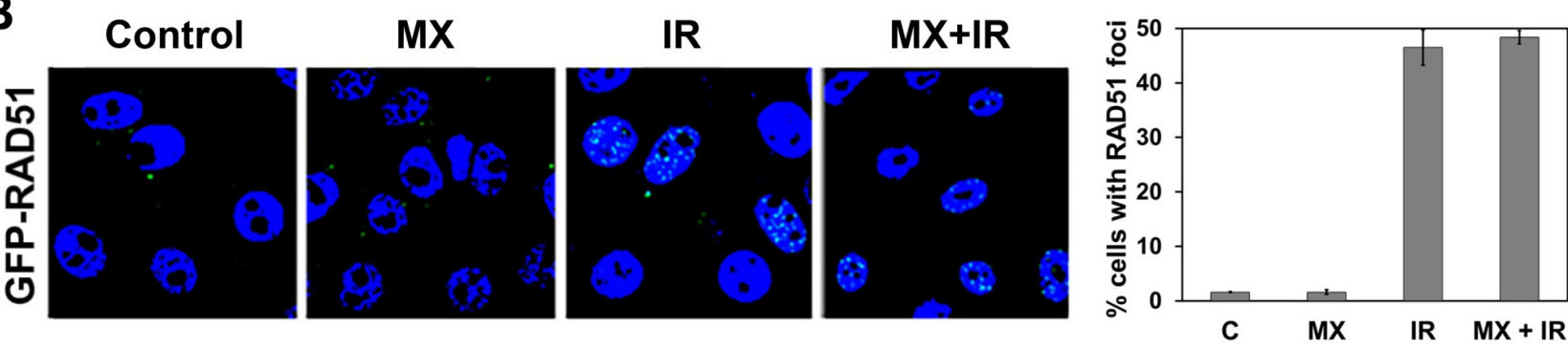

Fig 8. Effect of RAD52 inhibitor mitoxantrone on radiation-induced GFP-RAD52 and GFP-RAD51 foci formation in the HR-proficient ovarian cancer cells. PE01 C4-2 cells constitutively expressing (A) GFP-RAD52 and (B) GFP-RAD51 were treated with mitoxantrone (MX, $3 \mathrm{nM}$ ) alone, radiation alone (IR, $15 \mathrm{~Gy}$, RAD Source RS2000) or both. Cells without mitoxantrone and radiation (labeled C) were controls. The average percent of cells with foci (more than 5 foci per cell) are graphed from three independent experiments. More than 30 cells per experiment were analyzed. Error bars represent standard deviation. GFP-RAD52 and GFP-RAD51 were stably expressed individually in PE01 C4-2 (S5 Fig).

https://doi.org/10.1371/journal.pone.0248941.g008

II $\beta$ is expressed by quiescent cardiomyocytes [47]. Doxorubicin, on the other hand, targets both isoforms contributing to greater cardiotoxic risk and limited dose tolerance [48, 49]. Tolerance for high doses of mitoxantrone as part of multi-agent chemotherapy and better efficacy was reported in acute myeloid leukemia (AML) [50]. These properties of mitoxantrone are beneficial to patients, although still not without serious side effects. There is room for improvement.

A few newer studies support the notion that the action of mitoxantrone involves more than just the creation of DSBs. MTX appears to induce apoptosis in osteosarcoma cells through the regulation of the Akt/FOXO3 pathway [51]. Mitoxantrone inhibits PknB, PIM1, and protein kinase $\mathrm{C}$ as a nanomolar ATP competitive inhibitor [52-54]. Mitoxantrone also activates Tcell protein tyrosine phosphatase [55] and can inhibit VIM2 [56]. So mitoxantrone's effects are likely attributed to multiple targets that are vital to cell survival [51,53]. Mitoxantrone treated cells have also shown some changes to gene expression profiles $[57,58]$. Our western analysis before and after mitoxantrone treatment show that in PEO1 cells mitoxantrone reduces RAD52 protein levels significantly, there is a significant increase in DNA damage and this synthetic lethality is part of the mechanism for the low $\mathrm{EC}_{50}$ of $0.1 \mu \mathrm{M}$ in PEO1 cells (Fig $6 \mathrm{E}$ and $6 \mathrm{~F})$. This reduction in RAD52 levels is less significant in the C4-2 cell line that is a clone derived from PE01 that has a secondary mutation that restored BRCA2 function and there are low levels of DNA damage. These effects were not as significant in the other two HR-deficient cell lines (Fig 6A-6D). The mechanism of death in HCC1937 and UWB1 does not appear to rely as heavily on DNA damage from mitoxantrone and RAD52 levels increase or decrease but remain high. The exact mechanism for how mitoxantrone alters RAD52 protein levels, specifically or not, is not known.

While there have been a few reports about quinacrine as an anti-cancer agent, there is limited knowledge regarding the mechanism of its action against cancer. Quinacrine has been 


\section{A Control}

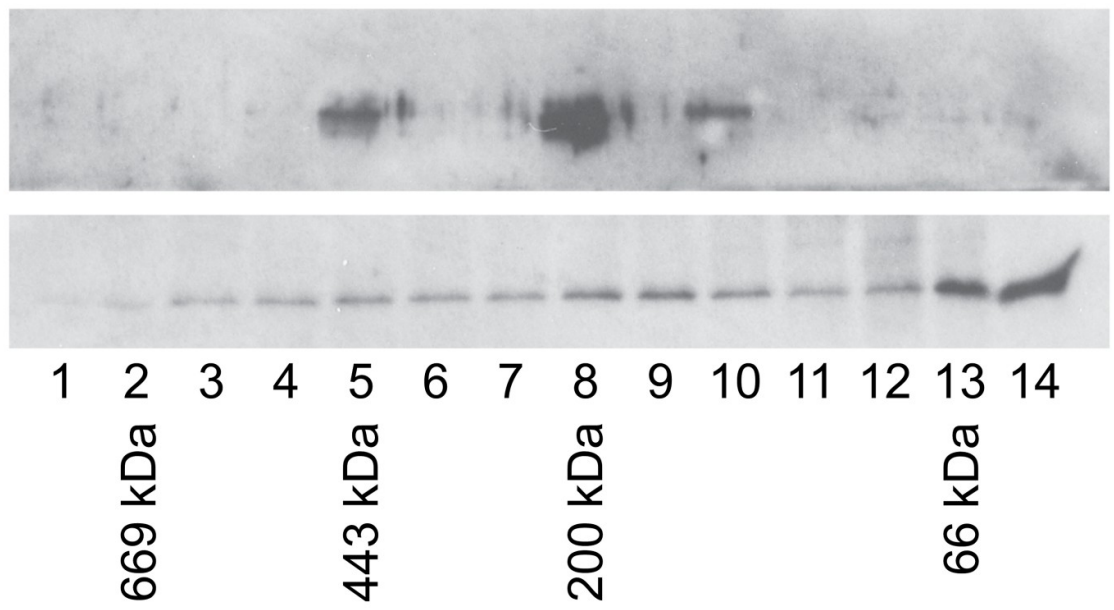

\section{B MTX at $3 \mathrm{nM}$}

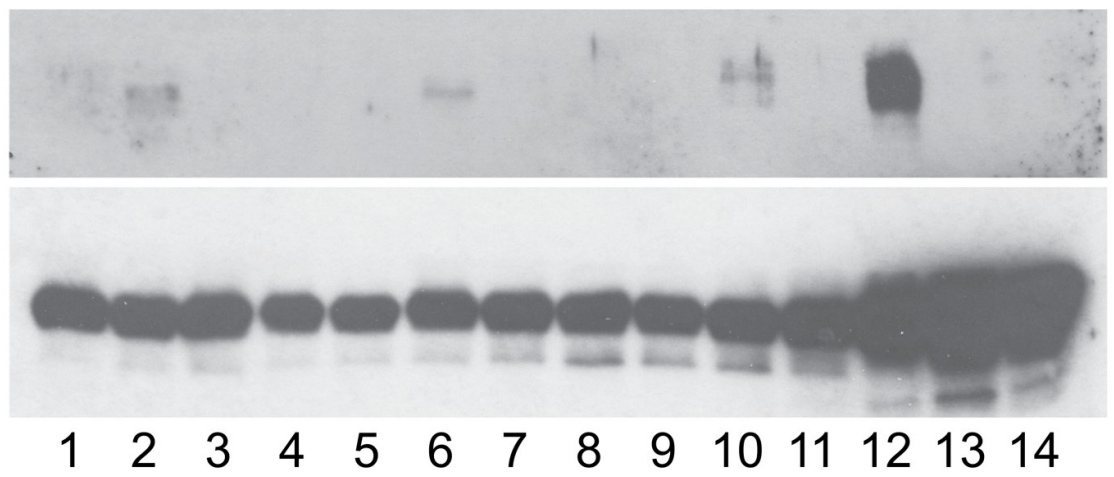

RAD52

RPA (p32)

Fig 9. Mitoxantrone disrupts the RPA:RAD52 PPI in cells. (A) RAD52 was co-immunoprecipitated with RPA in the fractions 5, 8, and 10 in the control experiment. The elution positions of the molecular weight standards, thyroglobulin $(669 \mathrm{kDa})$, apoferritin (443 $\mathrm{kDa})$, beta-amylase $(200 \mathrm{kDa})$, and bovine serum albumin $(66 \mathrm{kDa})$, are indicated below the western blot. The data indicate that RAD52 and RPA were in complexes with sizes of $\sim 400 \mathrm{kDa}$ and $\sim 200 \mathrm{kDa}$ in the control. (B) The treatment of the cells with $3 \mathrm{nM}$ mitoxantrone resulted in the loss of the co-immunoprecipitation of RAD52 with RPA in the large complexex. These data suggest that mitoxantrone disrupted the interaction of RAD52 and RPA in cells.

https://doi.org/10.1371/journal.pone.0248941.g009

used extensively as an anti-malarial drug and has emerged recently in "drug repurposing" study as an active agent in subtypes of leukemia, colon and breast cancers [59-61]. It has also been found to inhibit topoisomerase [62]. A surprising case of a lasting complete pathological response to neoadjuvant chemotherapy by a woman presenting with an aggressive stage IV high-grade serous ovarian cancer (HGSC) with metastasis to colon and liver was reported [63]. This unusual response was attributed to receiving quinacrine within a therapeutic regime to treat a separate co-incidental condition of dermatomyositis. Initial assessments to understand the anti-cancer activity of quinacrine was attributed to quinacrine-induced autophagy [64]. It is noteworthy that HGSC cells were used in this study, a subtype of ovarian cancer that has HR-deficiency $50 \%$ of the time [65], although the HR status of this particular patient is unclear. Our results revealed RAD52-mediated DNA repair as a potential new target of quinacrine in addition to other known targets. 
Topoisomerase II inhibitors exert their action by trapping topoisomerase at DSB ends and inducing DSBs. The accumulation of DSBs by topoisomerase inhibitors is toxic to BRCA-deficient cancer cells. In fact, it has been reported that BRCA-deficient cancer cell lines are sensitive to various topoisomerase inhibitors, including etoposide [66]. In addition to the formation of DSBs, trapped topoisomerases at DSB ends form a highly toxic protein-DNA complex that could prevent DNA repair proteins from accessing the DSB ends to initiate DSB repair. Interestingly, BRCA1, along with MRE11 and CtIP, promotes the removal of the trapped topoisomerases to initiate a resection process in HR repair [67-69]. Therefore, BRCA1-deficient cancer cells show high sensitivity to topoisomerase inhibitors. Our results indicate that the simultaneous inhibition of RAD52-mediated DNA repair with the induction of DSBs appears to exaggerate the cytotoxicity of mitoxantrone and doxorubicin in BRCA1deficient cancer cell lines.

Resistance to PARPi in BRCA-deficient cancer cells, before or after the treatment with PARPi, is a major issue. Recent studies revealed some mechanistic aspects of the PARPi resistance. Regaining HR and fork protection by inactivation of 53BP1, RIF1, REV7, or a Shieldin, and PTIP, respectively, results in resistance to PARPi in BRCA1-deficient cancer cells [70-79]. Our results demonstrate that our RAD52 inhibitors selectively kill PARPi-resistant BRCA1-deficient cell lines (Figs 2 and 3). Two of the cell lines we used in this study, UWB1-SYr12 and -UWB1-SYr13, obtained resistance to PARPi by acquiring ATR-dependent, but BRCA1-independent HR and fork protection [43]. Thus, RAD52 might play a pivotal role in these ATRdependent DNA repair pathways. The results also suggest a potential of RAD52 inhibitors to treat a wide range of HR-deficient cancers with or without PARPi-resistance.

\section{Materials and methods}

\section{Screening of chemical libraries with fluorescence-based protein-protein interaction assay (FluorIA)}

A newly developed fluorescence-based assay for detecting protein-protein interactions, FluorIA was used to identify SMIs of RPA:RAD52 PPI. The detailed FluorIA protocol is published elsewhere [39]. Briefly, 384-well plates (Thermo Fisher Scientific, \#460518) were coated with purified RPA. Then compounds or controls were added and incubated with freshly prepared GFP-RAD52. RAD52(1-303) without GFP-tag and buffer (including DMSO) only were used as controls. Then the relative fluorescence (RFU) was measured using a POLARstar OPTIMA plate reader (BMG LABTECH) on emptied plates at an excitation/emission (for eGFP) of 485/520 $\mathrm{nm}$ at 2500 gain setting.

Three chemical libraries the 355-member SelleckChem Kinase Inhibitor Library, the 1200-member Prestwick Chemical Library, and the 100,000-member ChemBridge library were used for the screening. The screening of the SelleckChem Kinase Inhibitor and the Prestwick libraries were performed at 10 and $100 \mu \mathrm{M}$ each in duplicate. The screening of the ChemBridge library was conducted at $100 \mu \mathrm{M}$. Compounds that inhibit $50 \%$ or more of the binding of GFP-RAD52 to RPA compared to controls were considered as hits. The statistical criteria for a hit were fully described in Al-Mugotir et al. [39]. Each hit was verified in triplicate at 10 and $100 \mu \mathrm{M}$.

The in vitro $\mathrm{EC}_{50}$ value of each hit was determined with FluorIA. The chemicals were serially diluted by two-fold increments from 0.030 to $500 \mu \mathrm{M}$ and analyzed in triplicate with FluorIA. RAD52(1-303) was used as a positive control and buffer with DMSO was used as a negative control. Candidate SMIs with strong inhibition were purchased, and a 1D NMR analysis was carried out to verify their identities. The eleven candidates SMIs were purchased as follows: 5137134, 5246481, 52614577,5316833, 5373030, and 7623574 from Chembridge 
HIT2LEAD, 5989499 from Wuxi lab network, 5375405 from Aronis, quinacrine and mitoxantrone from Sigma Aldrich, and doxorubicin from LC labs. D-I03 was purchased from Molport. Their effectiveness in inhibiting the RPA:RAD52 PPI was confirmed after purchase with the FluorIA as described above (S1 Fig).

\section{Cancer cell lines}

The HCC1937 cell line (a gift from Dr. Simon Powell Memorial Sloan Kettering (MSK), New York) was derived from a mammary gland primary ductal carcinoma at the early onset of a tumor. This TNBC patient carried a germline mutation in $B R C A 1$, resulting in carboxy-terminal truncated protein and loss of the second $B R C A 1$ allele. $B R C A 1$-restored and empty vector cell lines were also obtained by transfection of a vector containing a full-length human $B R C A 1$ cDNA or an empty vector, respectively. The HCC1937 cell lines were cultured as described [66].

BRCA2-deficient PE01 cell line (a gift from Dr. Toshiyasu Taniguchi, Tokai University, Japan) were derived from an ovarian cancer patient. BRCA2-proficient "revertant" cell line, C4-2 is one of eight clones derived from PE01 that has acquired resistance to both cisplatin and PARPi due to a secondary mutation that restored the BRCA2 function [62]. PE01 and PE01 C4-2 were grown and maintained in DMEM high glucose (Hyclone) supplemented with $10 \%$ Fetal Bovine Serum (FBS, Invitrogen).

UWB1.289 (a gift from Dr. Lee Zou, Harvard Medical School, Boston, MA) were derived from a serous ovarian carcinoma with a germline BRCA1 mutation and a deletion of the wildtype allele. UWB1.289+BRCA1 is a cell line with stable expression of the wild-type BRCA1 yielding partial correction of DNA damage response [80]. Two PARP-resistant cell lines, SYr12 and SYr13, were derived from the UWB1.289. The Mammary Epithelial growth media, along with SupplementMix solution for UWB1 cell lines, were obtained from PromoCell $\mathrm{GmbH}$ and mixed as described $[43,80]$.

\section{Cell viability assay}

Cells were seeded $5 \times 10^{3}$ cells per well in 96-well plates in a $90 \mu \mathrm{L}$ volume per well one day before treatment. Cells in 96-well plates were incubated with increasing concentrations of the compound or vehicle control (1\% DMSO) for 72 hours. Each treatment plate contained nine concentrations of a compound in sextuplicate. Growth inhibition was determined using PrestoBlue reagent (Life Technologies, \#A13261). Fluorescent measurements were taken using a Spectramax M5 plate reader (MDS). To assess cells' replication in the absence of compounds as a control, six wells on each plate were treated with vehicle to be read in triplicate at the initial treatment day $\left(\mathrm{T}_{0}\right)$ and at 72 -hour read $\left(\mathrm{T}_{100}\right)$.

\section{Simple western analysis}

For western analysis, each cell line was grown and treated as described above. Protein levels were measured in lysates by size separation with a ProteinSimple PeggySue instrument following the manufacturer's recommendations. Lysates were prepared using the NanoPro Cell Lysis Kit with Bicine/CHAPS (ProteinSimple CBS403) at $0.75 \mathrm{mg} / \mathrm{mL}$ concentration when mixed with master mix (containing SDS, DTT and fluorescent molecular weight markers; ProteinSimple PS-FL01-8) and heated for $5 \mathrm{~min}$ at $95^{\circ} \mathrm{C}$. Electrophoretic nanocapillary size separation of proteins was performed using default settings. After separation, UV light cross-linked proteins to the capillary wall. Capillaries were then washed and incubated with primary antibodies, washed, and incubated with anti-rabbit secondary antibody conjugated with HRP (ProteinSimple DM-001). Finally, luminol and peroxide were applied to generate 
chemoluminescence which was imaged by a CCD camera. Primary antibody concentrations were optimized and were diluted as follows: Abcam anti-RAD52 antibody (ab18263, diluted 1:25), R\&D Systems Human Phospho-histone H2AX (S139) antibody (AF2288, diluted 1:100), and Cell Signalling Technology Pan-Actin antibody (\#4968, diluted 1:2500).

The Simple western data were processed and analyzed with ProteinSimple Compass software. Peak areas were calculated using dropped lines. Each lysate was analyzed for RAD52 and $\gamma \mathrm{H} 2 \mathrm{AX}$ levels three times and for Actin two times (see S2 Fig). Replicate peak areas for RAD52 and $\gamma \mathrm{H} 2 \mathrm{AX}$ were averaged, divided by the average Actin peak area of that sample, multiplied by 100 and graphed using SigmaPlot 7.0.

\section{Statistical analysis}

Statistically significant differences in the data were determined using the Analysis of Variance (ANOVA) Single Factor from the Data Analysis package in Microsoft Excel 2016. In Excel, the ANOVA Single Factor is implemented as an F-Test which allows for the simultaneous analysis of multiple groups of data. In our case, we are only comparing two groups for each dosage experiment, so the F-Test is effectively a T-Test. For differences to be significant we required a $\mathrm{P}$ Value of less than 0.05 and $\mathrm{F}$ must be higher than $\mathrm{F}$ critical

\section{GFP-RAD52 and GFP-RAD51 foci formation}

GFP-RAD52 and GFP-RAD51 were stably expressed individually in the HR-restored PE01 C4-2 (S3 Fig). Each cell line was seeded on a coverslip at $10^{5}$ cells per well in a 24-well plate. After the 24 hour incubation, the cells were pre-incubated with mitoxantrone for 2 hours, then irradiated with X-ray at 15 Gy with the RS-2000 Irradiator. After $2 \sim 8$ hours of the irradiation, the cells were fixed in 10\% formaldehyde solution at room temperature for $30 \mathrm{~min}$, followed by $10 \mathrm{~min}$ incubation in PBS containing $0.5 \%$ Triton X-100. After staining with $1 \mu \mathrm{g} / \mathrm{ml}$ H1399 Hoechst dye solution, each coverslip was mounted on a slide. GFP proteins were detected with a Zeiss 710 Confocal Laser Scanning Microscope, and images were processed using Zeiss ZEN software. A cell contained more than 5 foci was considered as positive.

\section{Cell-based DSB repair assays}

Single strand annealing (SSA) activity and homologous recombination (HR) activity were measured with cell-based DSB repair assays [17]. The U2OS-SA cell line carries the chromosomally integrated SA-GFP reporter and U2OS-DR with chromosomally integrated DR-GFP reporter were used to measure SSA and HR activity, respectively (generous gifts from Dr. Jeremy Stark, Beckman Research Institute of the City of Hope,). U2OS-SA was seeded at $10^{5}$ cells per well, and U2OS-DR was seeded at $5 \times 10^{4}$ cells per well in a 12-well plate one day before transfection. U2OS-SA and U2OS-DR were grown and maintained in DMEM high glucose (Hyclone) supplemented with 10\% Fetal Bovine Serum (FBS, Invitrogen). RAD52 inhibitors were added to the cells 2 hours before the transfection. The expression plasmid of I-SceI endonuclease (a generous gift from Dr. Maria Jasin at Memorial Sloan Kettering Cancer Center) was transfected to introduce DSBs. Each DSB repair activity was determined by FACS three days after transfection. DSB repair activity was also measured by western blots. The cell lysate was prepared from cells from each well. Expressions of GFP and the I-SceI endonuclease (HA-tagged) were detected with anti-GFP antibody (GenScript A01388-40) and anti-HA antibody (COVANCE MMS-101R) after 12\% SDS-PAGE. GAPDH detected by anti-GAPDH antibody (Bethyl Laboratories, A300-639A) was used as a loading control. After normalizing the signals by GAPDH using ImageJ, a ratio of GFP/HA was calculated and used as the DSB repair activity. 


\section{Mitoxantrone effect on RPA:RAD52 complex}

U2OS cells $\left(10^{6}\right.$ cells) were seeded in a $100 \mathrm{~mm}$ dish and grown overnight. The cells were treated with the indicated concentrations of mitoxantrone (MTX) for 24 hours. The cell lysate was prepared in $100 \mu \mathrm{l}$ of lysis buffer (PBS with $0.5 \%$ NP40, 0.5\% Triton X100, 1 mM DTT, protease and phosphatase inhibitors, and $10 \%$ glycerol). After mixing with $100 \mu \mathrm{l}$ cold PBS, the lysate was incubated with $100 \mu \mathrm{l}$ of DEAE sepharose (GE Life Sciences) for 2 hours at $4^{\circ} \mathrm{C}$ with rotation. An unbound fraction from DEAE sepharose ( 200 $\mu \mathrm{l})$ was diluted with $200 \mu \mathrm{l}$ of PBS and half of the mixture was fractionated with Superdex200 (GE Life Sciences) using PBS as elution buffer. Each fraction was incubated with anti-RPA (p32) antibody conjugated with biotin (NeoMarkers, MS-691-B0) at $4^{\circ} \mathrm{C}$ overnight, then incubated with Streptavidin-magnetic beads (Promega \#Z5481) for one hour at $4^{\circ} \mathrm{C}$ with rotation. After washing with PBS, the immunoprecipitated proteins were eluted with 1xSDS loading dye and separated by $10 \%$ SDS-PAGE. RAD52 and RPA (p32) were detected by western blotting with anti-RAD52 antibody (LS-C42570, LSBio) and anti-RPA2 antibody (A300-244A, Bethyl Laboratories), respectively.

\section{Supporting information}

S1 Fig. Validation experiments of eleven hits with the FlourIA. Sixteen treatment concentrations were used (0.030-500 $\mu \mathrm{M})$ increasing by two-fold increments of each molecule/drug obtained as a hit in HTS FluorIA. RAD52(1-303) without GFP-tag and buffer (including DMSO) only were used as controls. Percent inhibition was calculated as follows: [(RFU $\mathrm{RMI}_{\mathrm{S}}$ $\left.\left.\mathrm{RFU}_{\mathrm{RAD52(1-303)}}\right) /\left(\mathrm{RFU}_{\mathrm{DMSO}}-\mathrm{RFU}_{\mathrm{RAD52(1-303)}}\right)\right]^{*} 100$, where $\mathrm{RFU}$ is relative fluorescence unit. An average of triplicate measurements was used. The treatment points for quinacrine and doxorubicin beyond $125 \mu \mathrm{M}$ were showing characteristics of aggregation and were not used.

(TIF)

S2 Fig. Simple Western analysis of cell lines with and without mitoxantrone treatment. Data were collected on a nanocapillary PeggySue instrument and displayed with Compass software (Protein Simple) in "lane" mode. (A) Results from Abcam anti-RAD52 antibody (ab18263, diluted 1:25). Each sample was run three times. The RAD52 band at 56-58 kDa was confirmed using Phoenix cells (ATCC) overexpressing human RAD52 (not shown). (B) Results from R\&D Systems Human Phospho-histone H2AX (S139) antibody (AF2288, diluted 1:100). Each sample was run three times and the band at $25 \mathrm{kDa}$ is shown. (C) Results from Cell Signaling Technology Pan-Actin antibody (4968, diluted 1:2500). Each sample was run two times and the band at $48 \mathrm{kDa}$ is shown. (TIF)

S3 Fig. FACS analysis of cell-based double strand breaks (DSB) repair assay. DSB repair activity by single strand annealing (SSA) or homologous recombination (HR) in MTX-treated GFP-reporter U2OS-SA and U2OS-DR respectively are measured by FACS analysis. Treated and untreated cells are sorted and repair activity by either pathway is measured by increased green fluorescence (y-axis). Green cells are calculated as a percent from total cells within each contour plot.

(TIF)

S4 Fig. Representative western blots for detecting DSB repair activities. SSA (panel A) and HR (panel B) activity were determined by western blotting. The expression levels of I-SceI and GFP were determined by western blots. GADPH was used as a loading control. C: control experiments without I-SceI expression. Lanes 1-3; three independent experiments without 
mitoxantrone-treatment, lanes 4-6; three independent experiments with $3 \mathrm{nM}$ mitoxantrone treatment. Cell lysate from each treatment was separated by $12 \%$ SDS-PAGE. Two identical samples were analyzed for one set of experiments, and one gel was used for I-SceI expression and the other was used for GFP expression. I-SceI and GFP signals were normalized by the signals of GAPDH in each lane. The repair activity in each lane was expressed as a ratio of normalized GFP/normalized I-SceI.

(TIF)

S5 Fig. Expression of GFP-RAD52 and GFP-RAD51 in PE01 C4-2 cells. (A) GFP-RAD52 or GPF-RAD51 were immuno-precipitated by anti-GFP antibody (SCBT B-2), and the immunocomplexes were analyzed on 8\% SDS-PAGE followed by the western blots with anti-RAD51 antibody (SCBT H92) and anti-RAD52 antibody (LSBio aa360-375). (B) Expression levels of GFP-RAD52 and GFP-RAD51. Cell lysates from control cells (lane 1), GFP-RAD51 expressing cells (lane 2), and GFP-RAD52 expressing cells (lane 3) were analyzed on 8\% SDS-PAGE followed by western blots with anti-GFP antibody (GenScript pAb Rabbit). The arrows indicate GFP-RAD51 (lane 2) and GFP-RAD52 (lane 3). GAPDH was used as a loading control.

S1 Raw images.

(PDF)

\section{Acknowledgments}

We thank William Lutz for his technical assistance. We also thank Dr. David Kelly and Amy Wells at the UNMC Fred \& Pamela Buffet Cancer Center Molecular Biology/HTS Core Facility for access to the chemical libraries and instrumentation. We also thank the University of Nebraska Medical Center Advanced Microscopy Core Facility, Flow Cytometry Research Facility, and Biological Irradiator Core Facility.

\section{Author Contributions}

Conceptualization: Amarnath Natarajan, Tadayoshi Bessho, Gloria E. O. Borgstahl.

Funding acquisition: Tadayoshi Bessho, Gloria E. O. Borgstahl.

Investigation: Mona Al-Mugotir, Joseph George, Mika Bessho, Dhananjaya Pal, Lucas Struble, Carol Kolar, Sandeep Rana, Tadayoshi Bessho.

Methodology: Tadayoshi Bessho.

Supervision: Gloria E. O. Borgstahl.

Validation: Sandeep Rana.

Visualization: Tadayoshi Bessho.

Writing - original draft: Mona Al-Mugotir, Gloria E. O. Borgstahl.

Writing - review \& editing: Jeffrey J. Lovelace, Tadayoshi Bessho, Gloria E. O. Borgstahl.

\section{References}

1. Dietlein F, Thelen L, Reinhardt HC. Cancer-specific defects in DNA repair pathways as targets for personalized therapeutic approaches. Trends Genet. 2014; 30(8):326-39. https://doi.org/10.1016/j.tig. 2014.06.003 PMID: 25017190 
2. Shaheen M, Allen C, Nickoloff JA, Hromas R. Synthetic lethality: exploiting the addiction of cancer to DNA repair. Blood. 2011; 117(23):6074-82. https://doi.org/10.1182/blood-2011-01-313734 PMID: 21441464

3. Cancer Genome Atlas Research N. Integrated genomic analyses of ovarian carcinoma. Nature. 2011; 474(7353):609-15. https://doi.org/10.1038/nature10166 PMID: 21720365

4. Guestini F, McNamara KM, Ishida T, Sasano H. Triple negative breast cancer chemosensitivity and chemoresistance: current advances in biomarkers indentification. Expert Opin Ther Targets. 2016; 20(6):705-20. https://doi.org/10.1517/14728222.2016.1125469 PMID: 26607563

5. Audeh MW, Carmichael J, Penson RT, Friedlander M, Powell B, Bell-McGuinn KM, et al. Oral poly (ADP-ribose) polymerase inhibitor olaparib in patients with BRCA1 or BRCA2 mutations and recurrent ovarian cancer: a proof-of-concept trial. Lancet. 2010; 376(9737):245-51. https://doi.org/10.1016/ S0140-6736(10)60893-8 PMID: 20609468

6. Banerjee S, Kaye SB, Ashworth A. Making the best of PARP inhibitors in ovarian cancer. Nat Rev Clin Oncol. 2010; 7(9):508-19. https://doi.org/10.1038/nrclinonc.2010.116 PMID: 20700108

7. Domagala $P$, Hybiak J, Cybulski C, Lubinski J. BRCA1/2-negative hereditary triple-negative breast cancers exhibit BRCAness. International journal of cancer Journal international du cancer. 2017; 140(7):1545-50. https://doi.org/10.1002/ijc.30570 PMID: 27943282

8. Morales J, Li L, Fattah FJ, Dong Y, Bey EA, Patel M, et al. Review of poly (ADP-ribose) polymerase (PARP) mechanisms of action and rationale for targeting in cancer and other diseases. Crit Rev Eukaryot Gene Expr. 2014; 24(1):15-28. https://doi.org/10.1615/critreveukaryotgeneexpr.2013006875 PMID: 24579667

9. Lord CJ, Ashworth A. Targeted therapy for cancer using PARP inhibitors. Curr Opin Pharmacol. 2008; 8(4):363-9. https://doi.org/10.1016/j.coph.2008.06.016 PMID: 18644251

10. Pettitt SJ, Lord CJ. Dissecting PARP inhibitor resistance with functional genomics. Curr Opin Genet Dev. 2019; 54:55-63. https://doi.org/10.1016/j.gde.2019.03.001 PMID: 30954761

11. Ashworth A, Lord CJ. Synthetic lethal therapies for cancer: what's next after PARP inhibitors? Nat Rev Clin Oncol. 2018; 15(9):564-76. https://doi.org/10.1038/s41571-018-0055-6 PMID: 29955114

12. Liao H, Ji F, Helleday $T$, Ying S. Mechanisms for stalled replication fork stabilization: new targets for synthetic lethality strategies in cancer treatments. EMBO Rep. 2018; 19(9). https://doi.org/10.15252/ embr.201846263 PMID: 30108055

13. Feng Z, Scott SP, Bussen W, Sharma GG, Guo G, Pandita TK, et al. Rad52 inactivation is synthetically lethal with BRCA2 deficiency. Proceedings of the National Academy of Sciences of the United States of America. 2011; 108(2):686-91. https://doi.org/10.1073/pnas.1010959107 PMID: 21148102

14. Lok BH, Carley AC, Tchang $B$, Powell SN. RAD52 inactivation is synthetically lethal with deficiencies in BRCA1 and PALB2 in addition to BRCA2 through RAD51-mediated homologous recombination. Oncogene. 2013; 32(30):3552-8. https://doi.org/10.1038/onc.2012.391 PMID: 22964643

15. Hanamshet K, Mazina OM, Mazin AV. Reappearance from Obscurity: Mammalian Rad52 in Homologous Recombination. Genes (Basel). 2016; 7(9). https://doi.org/10.3390/genes7090063 PMID: 27649245

16. Lok BH, Powell SN. Molecular pathways: understanding the role of Rad52 in homologous recombination for therapeutic advancement. Clinical cancer research: an official journal of the American Association for Cancer Research. 2012; 18(23):6400-6.

17. Stark JM, Pierce AJ, Oh J, Pastink A, Jasin M. Genetic steps of mammalian homologous repair with distinct mutagenic consequences. Mol Cell Biol. 2004; 24(21):9305-16. https://doi.org/10.1128/MCB.24. 21.9305-9316.2004 PMID: 15485900

18. Sotiriou SK, Kamileri I, Lugli N, Evangelou K, Da-Re C, Huber F, et al. Mammalian RAD52 Functions in Break-Induced Replication Repair of Collapsed DNA Replication Forks. Mol Cell. 2016; 64(6):1127-34 https://doi.org/10.1016/j.molcel.2016.10.038 PMID: 27984746

19. Bhowmick R, Minocherhomji S, Hickson ID. RAD52 Facilitates Mitotic DNA Synthesis Following Replication Stress. Mol Cell. 2016; 64(6):1117-26. https://doi.org/10.1016/j.molcel.2016.10.037 PMID: 27984745

20. Keskin $\mathrm{H}$, Shen $\mathrm{Y}$, Huang $\mathrm{F}$, Patel $\mathrm{M}$, Yang $\mathrm{T}$, Ashley $\mathrm{K}$, et al. Transcript-RNA-templated DNA recombination and repair. Nature. 2014; 515(7527):436-9. https://doi.org/10.1038/nature13682 PMID: 25186730

21. Mazina OM, Keskin $H$, Hanamshet $K$, Storici $F$, Mazin AV. Rad52 Inverse Strand Exchange Drives RNA-Templated DNA Double-Strand Break Repair. Mol Cell. 2017; 67(1):19-29 e3. https://doi.org/10 1016/j.molcel.2017.05.019 PMID: 28602639

22. Yasuhara $T$, Kato R, Hagiwara $Y$, Shiotani $B$, Yamauchi $M$, Nakada S, et al. Human Rad52 Promotes XPG-Mediated R-loop Processing to Initiate Transcription-Associated Homologous Recombination Repair. Cell. 2018; 175(2):558-70 e11. https://doi.org/10.1016/j.cell.2018.08.056 PMID: 30245011 
23. Liang Z, Ahn J, Guo D, Votaw JR, Shim H. MicroRNA-302 replacement therapy sensitizes breast cancer cells to ionizing radiation. Pharm Res. 2013; 30(4):1008-16. https://doi.org/10.1007/s11095-0120936-9 PMID: 23184229

24. Cramer-Morales K, Nieborowska-Skorska M, Scheibner K, Padget M, Irvine DA, Sliwinski T, et al. Personalized synthetic lethality induced by targeting RAD52 in leukemias identified by gene mutation and expression profile. Blood. 2013; 122(7):1293-304. https://doi.org/10.1182/blood-2013-05-501072 PMID: 23836560

25. Chandramouly G, McDevitt S, Sullivan K, Kent T, Luz A, Glickman JF, et al. Small-Molecule Disruption of RAD52 Rings as a Mechanism for Precision Medicine in BRCA-Deficient Cancers. Chem Biol. 2015; 22(11):1491-504. https://doi.org/10.1016/j.chembiol.2015.10.003 PMID: 26548611

26. Deng X, Prakash A, Dhar K, Baia GS, Kolar C, Oakley GG, et al. Human replication protein A-Rad52single-stranded DNA complex: stoichiometry and evidence for strand transfer regulation by phosphorylation. Biochemistry. 2009; 48(28):6633-43. https://doi.org/10.1021/bi900564k PMID: 19530647

27. Huang F, Goyal N, Sullivan K, Hanamshet K, Patel M, Mazina OM, et al. Targeting BRCA1- and BRCA2-deficient cells with RAD52 small molecule inhibitors. Nucleic Acids Res. 2016; 44(9):4189-99. https://doi.org/10.1093/nar/gkw087 PMID: 26873923

28. Hengel SR, Malacaria E, Folly da Silva Constantino L, Bain FE, Diaz A, Koch BG, et al. Small-molecule inhibitors identify the RAD52-ssDNA interaction as critical for recovery from replication stress and for survival of BRCA2 deficient cells. Elife. 2016; 5. https://doi.org/10.7554/eLife.14740 PMID: 27434671

29. Hengel SR, Spies MA, Spies M. Small-Molecule Inhibitors Targeting DNA Repair and DNA Repair Deficiency in Research and Cancer Therapy. Cell Chem Biol. 2017; 24(9):1101-19. https://doi.org/10.1016/ j.chembiol.2017.08.027 PMID: 28938088

30. Park MS, Ludwig DL, Stigger E, Lee SH. Physical interaction between human RAD52 and RPA is required for homologous recombination in mammalian cells. The Journal of biological chemistry. 1996; 271(31):18996-9000. https://doi.org/10.1074/jbc.271.31.18996 PMID: 8702565

31. Ranatunga W, Jackson D, Flowers IR 2nd, Borgstahl GE. Human RAD52 protein has extreme thermal stability. Biochemistry. 2001; 40(29):8557-62. https://doi.org/10.1021/bi0155089 PMID: 11456495

32. Kagawa W, Kurumizaka H, Ishitani R, Fukai S, Nureki O, Shibata T, et al. Crystal structure of the homologous-pairing domain from the human Rad52 recombinase in the undecameric form. Mol Cell. 2002; 10 (2):359-71. https://doi.org/10.1016/s1097-2765(02)00587-7 PMID: 12191481

33. Singleton MR, Wentzell LM, Liu Y, West SC, Wigley DB. Structure of the single-strand annealing domain of human RAD52 protein. Proceedings of the National Academy of Sciences of the United States of America. 2002; 99(21):13492-7. https://doi.org/10.1073/pnas.212449899 PMID: 12370410

34. Parsons CA, Baumann $P$, Van Dyck E, West SC. Precise binding of single-stranded DNA termini by human RAD52 protein. EMBO J. 2000; 19(15):4175-81. https://doi.org/10.1093/emboj/19.15.4175 PMID: 10921897

35. Saotome M, Saito K, Yasuda T, Ohtomo H, Sugiyama S, Nishimura Y, et al. Structural Basis of Homology-Directed DNA Repair Mediated by RAD52. iScience. 2018; 3:50-62. https://doi.org/10.1016/j.isci. 2018.04.005 PMID: 30428330

36. Jackson D, Dhar K, Wahl JK, Wold MS, Borgstahl GE. Analysis of the human replication protein A: Rad52 complex: evidence for crosstalk between RPA32, RPA70, Rad52 and DNA. Journal of molecular biology. 2002; 321(1):133-48. https://doi.org/10.1016/s0022-2836(02)00541-7 PMID: 12139939

37. Plate I, Hallwyl SC, Shi I, Krejci L, Muller C, Albertsen L, et al. Interaction with RPA is necessary for Rad52 repair center formation and for its mediator activity. The Journal of biological chemistry. 2008; 283(43):29077-85. https://doi.org/10.1074/jbc.M804881200 PMID: 18703507

38. Sugiyama T, New JH, Kowalczykowski SC. DNA annealing by RAD52 protein is stimulated by specific interaction with the complex of replication protein $A$ and single-stranded DNA. Proceedings of the National Academy of Sciences of the United States of America. 1998; 95(11):6049-54. https://doi.org/ 10.1073/pnas.95.11.6049 PMID: 9600915

39. Al-Mugotir M, Kolar C, Vance K, Kelly DL, Natarajan A, Borgstahl GEO. A simple fluorescent assay for the discovery of protein-protein interaction inhibitors. Anal Biochem. 2019; 569:46-52. https://doi.org/ 10.1016/j.ab.2019.01.010 PMID: 30707898

40. Drew Y, Mulligan EA, Vong WT, Thomas HD, Kahn S, Kyle S, et al. Therapeutic potential of poly(ADPribose) polymerase inhibitor AG014699 in human cancers with mutated or methylated BRCA1 or BRCA2. J Natl Cancer Inst. 2011; 103(4):334-46. https://doi.org/10.1093/jnci/djq509 PMID: 21183737

41. Lehmann BD, Bauer JA, Chen X, Sanders ME, Chakravarthy AB, Shyr Y, et al. Identification of human triple-negative breast cancer subtypes and preclinical models for selection of targeted therapies. $\mathrm{J}$ Clin Invest. 2011; 121(7):2750-67. https://doi.org/10.1172/JCI45014 PMID: 21633166 
42. Pierce A, McGowan PM, Cotter M, Mullooly M, O'Donovan N, Rani S, et al. Comparative antiproliferative effects of iniparib and olaparib on a panel of triple-negative and non-triple-negative breast cancer cell lines. Cancer Biol Ther. 2013; 14(6):537-45. https://doi.org/10.4161/cbt.24349 PMID: 23760496

43. Yazinski SA, Comaills V, Buisson R, Genois MM, Nguyen HD, Ho CK, et al. ATR inhibition disrupts rewired homologous recombination and fork protection pathways in PARP inhibitor-resistant BRCAdeficient cancer cells. Genes Dev. 2017; 31(3):318-32. https://doi.org/10.1101/gad.290957.116 PMID: 28242626

44. Lown JW, Hanstock CC, Bradley RD, Scraba DG. Interactions of the antitumor agents mitoxantrone and bisantrene with deoxyribonucleic acids studied by electron microscopy. Mol Pharmacol. 1984; 25(1):178-84. PMID: 6708933

45. Brana MF, Cacho M, Gradillas A, de Pascual-Teresa B, Ramos A. Intercalators as anticancer drugs Curr Pharm Des. 2001; 7(17):1745-80. https://doi.org/10.2174/1381612013397113 PMID: 11562309

46. Fry AM, Chresta CM, Davies SM, Walker MC, Harris AL, Hartley JA, et al. Relationship between topoisomerase II level and chemosensitivity in human tumor cell lines. Cancer Res. 1991; 51(24):6592-5. PMID: 1660343

47. Capranico G, Tinelli S, Austin CA, Fisher ML, Zunino F. Different patterns of gene expression of topoisomerase II isoforms in differentiated tissues during murine development. Biochimica et biophysica acta. 1992; 1132(1):43-8. https://doi.org/10.1016/0167-4781(92)90050-a PMID: 1380833

48. Lyu YL, Kerrigan JE, Lin CP, Azarova AM, Tsai YC, Ban Y, et al. Topoisomerase llbeta mediated DNA double-strand breaks: implications in doxorubicin cardiotoxicity and prevention by dexrazoxane. Cancer Res. 2007; 67(18):8839-46. https://doi.org/10.1158/0008-5472.CAN-07-1649 PMID: 17875725

49. Wiseman LR, Spencer CM. Mitoxantrone. A review of its pharmacology and clinical efficacy in the management of hormone-resistant advanced prostate cancer. Drugs Aging. 1997; 10(6):473-85. https:// doi.org/10.2165/00002512-199710060-00007 PMID: 9205852

50. Halpern AB, Walter RB. CLAG-M with dose-escalated mitoxantrone for adults with acute myeloid leukemia. Oncotarget. 2018; 9(93):36543-4. https://doi.org/10.18632/oncotarget.26383 PMID: 30564292

51. Park SH, Lee J, Kang MA, Jang KY, Kim JR. Mitoxantrone induces apoptosis in osteosarcoma cells through regulation of the Akt/FOXO3 pathway. Oncol Lett. 2018; 15(6):9687-96. https://doi.org/10. 3892/ol.2018.8547 PMID: 29928344

52. Takeuchi N, Nakamura $\mathrm{T}$, Takeuchi $\mathrm{F}$, Hashimoto $\mathrm{E}$, Yamamura $\mathrm{H}$. Inhibitory effect of mitoxantrone on activity of protein kinase $C$ and growth of HL60 cells. J Biochem. 1992; 112(6):762-7. https://doi.org/10. 1093/oxfordjournals.jbchem.a123972 PMID: 1295884

53. Wan X, Zhang W, Li L, Xie Y, Li W, Huang N. A new target for an old drug: identifying mitoxantrone as a nanomolar inhibitor of PIM1 kinase via kinome-wide selectivity modeling. Journal of medicinal chemistry. 2013; 56(6):2619-29. https://doi.org/10.1021/jm400045y PMID: 23442188

54. Wehenkel A, Fernandez P, Bellinzoni M, Catherinot V, Barilone N, Labesse G, et al. The structure of $\mathrm{PknB}$ in complex with mitoxantrone, an ATP-competitive inhibitor, suggests a mode of protein kinase regulation in mycobacteria. FEBS Lett. 2006; 580(13):3018-22. https://doi.org/10.1016/j.febslet.2006. 04.046 PMID: 16674948

55. Ylilauri M, Mattila E, Nurminen EM, Kapyla J, Niinivehmas SP, Maatta JA, et al. Molecular mechanism of T-cell protein tyrosine phosphatase (TCPTP) activation by mitoxantrone. Biochim Biophys Acta. 2013; 1834(10):1988-97. https://doi.org/10.1016/j.bbapap.2013.07.001 PMID: 23856547

56. Minond D, Saldanha SA, Subramaniam P, Spaargaren M, Spicer T, Fotsing JR, et al. Inhibitors of VIM2 by screening pharmacologically active and click-chemistry compound libraries. Bioorg Med Chem. 2009; 17(14):5027-37. https://doi.org/10.1016/j.bmc.2009.05.070 PMID: 19553129

57. Li S, Li R, Ma Y, Zhang C, Huang T, Zhu S. Transcriptome analysis of differentially expressed genes and pathways associated with mitoxantrone treatment prostate cancer. J Cell Mol Med. 2019; 23(3):1987-2000. https://doi.org/10.1111/jcmm.14100 PMID: 30592148

58. Liu L, Zhu H, Yan Y, Lv P, Wu W. Toxicity Evaluation and Biomarker Selection with Validated Reference Gene in Embryonic Zebrafish Exposed to Mitoxantrone. Int J Mol Sci. 2018; 19(11). https://doi.org/10. 3390/ijms19113516 PMID: 30413070

59. Das S, Tripathi N, Preet R, Siddharth S, Nayak A, Bharatam PV, et al. Quinacrine induces apoptosis in cancer cells by forming a functional bridge between TRAIL-DR5 complex and modulating the mitochondrial intrinsic cascade. Oncotarget. 2017; 8(1):248-67. https://doi.org/10.18632/oncotarget.11335 PMID: 27542249

60. Eriksson A, Osterroos A, Hassan S, Gullbo J, Rickardson L, Jarvius M, et al. Drug screen in patient cells suggests quinacrine to be repositioned for treatment of acute myeloid leukemia. Blood Cancer J. 2015; 5:e307. https://doi.org/10.1038/bcj.2015.31 PMID: 25885427 
61. Mohapatra P, Preet R, Das D, Satapathy SR, Choudhuri T, Wyatt MD, et al. Quinacrine-mediated autophagy and apoptosis in colon cancer cells is through a p53- and p21-dependent mechanism. Oncology research. 2012; 20(2-3):81-91. https://doi.org/10.3727/096504012x13473664562628 PMID: 23193914

62. Sakai W, Swisher EM, Jacquemont C, Chandramohan KV, Couch FJ, Langdon SP, et al. Functional restoration of BRCA2 protein by secondary BRCA2 mutations in BRCA2-mutated ovarian carcinoma. Cancer Res. 2009; 69(16):6381-6. https://doi.org/10.1158/0008-5472.CAN-09-1178 PMID: 19654294

63. Cadena I, Werth VP, Levine P, Yang A, Downey A, Curtin J, et al. Lasting pathologic complete response to chemotherapy for ovarian cancer after receiving antimalarials for dermatomyositis. Ecancermedicalscience. 2018; 12:837. https://doi.org/10.3332/ecancer.2018.837 PMID: 29910834

64. Jung D, Khurana A, Roy D, Kalogera E, Bakkum-Gamez J, Chien J, et al. Quinacrine upregulates p21/ p27 independent of p53 through autophagy-mediated downregulation of p62-Skp2 axis in ovarian cancer. Sci Rep. 2018; 8(1):2487. https://doi.org/10.1038/s41598-018-20531-w PMID: 29410485

65. George SH, Shaw P. BRCA and Early Events in the Development of Serous Ovarian Cancer. Front Oncol. 2014; 4:5. https://doi.org/10.3389/fonc.2014.00005 PMID: 24478985

66. Treszezamsky AD, Kachnic LA, Feng Z, Zhang J, Tokadjian C, Powell SN. BRCA1- and BRCA2deficient cells are sensitive to etoposide-induced DNA double-strand breaks via topoisomerase II. Cancer Res. 2007; 67(15):7078-81. https://doi.org/10.1158/0008-5472.CAN-07-0601 PMID: 17671173

67. Aparicio T, Baer R, Gottesman M, Gautier J. MRN, CtIP, and BRCA1 mediate repair of topoisomerase II-DNA adducts. J Cell Biol. 2016; 212(4):399-408. https://doi.org/10.1083/jcb.201504005 PMID: 26880199

68. Nakamura K, Kogame T, Oshiumi H, Shinohara A, Sumitomo Y, Agama K, et al. Collaborative action of Brca1 and CtIP in elimination of covalent modifications from double-strand breaks to facilitate subsequent break repair. PLoS Genet. 2010; 6(1):e1000828. https://doi.org/10.1371/journal.pgen.1000828 PMID: 20107609

69. Sasanuma H, Tsuda M, Morimoto S, Saha LK, Rahman MM, Kiyooka Y, et al. BRCA1 ensures genome integrity by eliminating estrogen-induced pathological topoisomerase II-DNA complexes. Proceedings of the National Academy of Sciences of the United States of America. 2018; 115(45):E10642-E51. https://doi.org/10.1073/pnas.1803177115 PMID: 30352856

70. Bunting SF, Callen E, Wong N, Chen HT, Polato F, Gunn A, et al. 53BP1 inhibits homologous recombination in Brca1-deficient cells by blocking resection of DNA breaks. Cell. 2010; 141(2):243-54. https:// doi.org/10.1016/j.cell.2010.03.012 PMID: 20362325

71. Chapman JR, Barral P, Vannier JB, Borel V, Steger M, Tomas-Loba A, et al. RIF1 is essential for 53BP1-dependent nonhomologous end joining and suppression of DNA double-strand break resection. Mol Cell. 2013; 49(5):858-71. https://doi.org/10.1016/j.molcel.2013.01.002 PMID: 23333305

72. Escribano-Diaz C, Orthwein A, Fradet-Turcotte A, Xing M, Young JT, Tkac J, et al. A cell cycle-dependent regulatory circuit composed of 53BP1-RIF1 and BRCA1-CtIP controls DNA repair pathway choice. Mol Cell. 2013; 49(5):872-83. https://doi.org/10.1016/j.molcel.2013.01.001 PMID: 23333306

73. Ghezraoui $\mathrm{H}$, Oliveira $\mathrm{C}$, Becker JR, Bilham K, Moralli $\mathrm{D}$, Anzilotti $\mathrm{C}$, et al. 53BP1 cooperation with the REV7-shieldin complex underpins DNA structure-specific NHEJ. Nature. 2018; 560(7716):122-7. https://doi.org/10.1038/s41586-018-0362-1 PMID: 30046110

74. Gupta R, Somyajit K, Narita T, Maskey E, Stanlie A, Kremer M, et al. DNA Repair Network Analysis Reveals Shieldin as a Key Regulator of NHEJ and PARP Inhibitor Sensitivity. Cell. 2018; 173(4):97288 e23. https://doi.org/10.1016/j.cell.2018.03.050 PMID: 29656893

75. Mirman Z, Lottersberger F, Takai H, Kibe T, Gong Y, Takai K, et al. 53BP1-RIF1-shieldin counteracts DSB resection through CST- and Polalpha-dependent fill-in. Nature. 2018; 560(7716):112-6. https:// doi.org/10.1038/s41586-018-0324-7 PMID: 30022158

76. Noordermeer SM, Adam S, Setiaputra D, Barazas M, Pettitt SJ, Ling AK, et al. The shieldin complex mediates 53BP1-dependent DNA repair. Nature. 2018; 560(7716):117-21. https://doi.org/10.1038/ s41586-018-0340-7 PMID: 30022168

77. Xu G, Chapman JR, Brandsma I, Yuan J, Mistrik M, Bouwman P, et al. REV7 counteracts DNA doublestrand break resection and affects PARP inhibition. Nature. 2015; 521(7553):541-4. https://doi.org/10. 1038/nature14328 PMID: 25799992

78. Zimmermann M, Lottersberger F, Buonomo SB, Sfeir A, de Lange T. 53BP1 regulates DSB repair using Rif1 to control 5' end resection. Science. 2013; 339(6120):700-4. https://doi.org/10.1126/science. 1231573 PMID: 23306437 
79. Dev H, Chiang TW, Lescale C, de Krijger I, Martin AG, Pilger D, et al. Shieldin complex promotes DNA end-joining and counters homologous recombination in BRCA1-null cells. Nat Cell Biol. 2018; 20(8):954-65. https://doi.org/10.1038/s41556-018-0140-1 PMID: 30022119

80. DelloRusso C, Welcsh PL, Wang W, Garcia RL, King MC, Swisher EM. Functional characterization of a novel BRCA1-null ovarian cancer cell line in response to ionizing radiation. Mol Cancer Res. 2007; 5(1):35-45. https://doi.org/10.1158/1541-7786.MCR-06-0234 PMID: 17259345 